This item was submitted to Loughborough's Research Repository by the author.

Items in Figshare are protected by copyright, with all rights reserved, unless otherwise indicated.

\title{
Oxygen diffusion and crack growth for a nickel-based superalloy under fatigue-oxidation conditions
}

PLEASE CITE THE PUBLISHED VERSION

http://dx.doi.org/10.1016/j.msea.2012.12.088

PUBLISHER

(C) Elsevier

VERSION

AM (Accepted Manuscript)

LICENCE

CC BY-NC-ND 4.0

\section{REPOSITORY RECORD}

Karabela, A., Liguo Zhao, B. Lin, Jie Tong, and M.C. Hardy. 2019. "Oxygen Diffusion and Crack Growth for a Nickel-based Superalloy Under Fatigue-oxidation Conditions”. figshare. https://hdl.handle.net/2134/11664. 
This item was submitted to Loughborough's Institutional Repository (https://dspace.lboro.ac.uk/) by the author and is made available under the following Creative Commons Licence conditions.

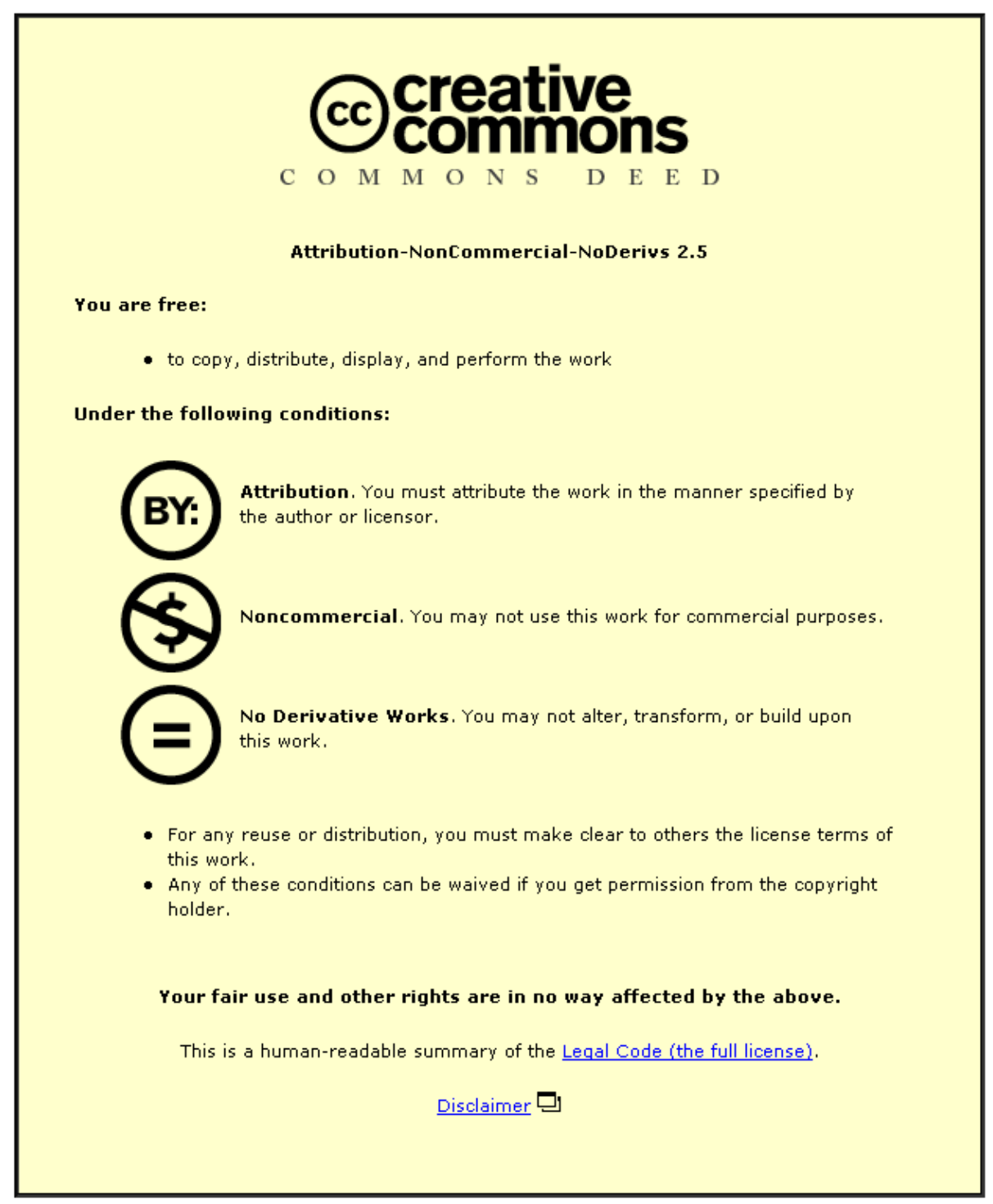

For the full text of this licence, please go to: http://creativecommons.org/licenses/by-nc-nd/2.5/ 


\title{
Oxygen Diffusion and Crack Growth for a Nickel-Based Superalloy under Fatigue-Oxidation Conditions
}

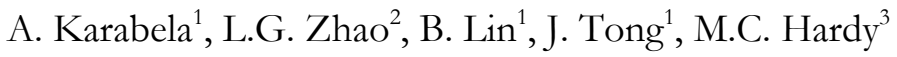 \\ 1. School of Engineering, University of Portsmouth, Anglesea Building, Anglesea Road, Portsmouth, \\ PO1 3DJ, UK \\ 2. Wolfson School of Mechanical and Manufacturing Engineering, Loughborough University, \\ Loughborough, LE11 3TU, UK \\ 3. Rolls-Royce plc, Elton Road, Derby, DE24 8BJ, UK
}

\begin{abstract}
Advanced microscopy characterisation and numerical modelling have been carried out to investigate oxygen diffusion and crack growth in a nickel-based superalloy under fatigue-oxidation conditions. Penetration of oxygen into the material and the associated internal oxidation, which leads to material embrittlement and failure, have been found from Focused Ion Beam (FIB) examinations. Applied fatigue loading tends to enhance the extent of internal oxidation for temperatures at $750^{\circ} \mathrm{C}$ and above. Using a submodelling technique, finite element analyses of oxygen penetration at grain level have been carried out to quantify the fatigue-oxidation damage and calibrate the diffusion parameters based on the measurements of maximum depth of internal oxidation. The grain microstructure was considered explicitly in the finite element model, where the grain boundary was taken as the primary path for oxygen diffusion. A sequentially coupled mechanical-diffusion analysis was adopted to account for the effects of deformation on diffusion during fatigue loading, for which the material constitutive behaviour was described by a crystal plasticity model at grain level. Prediction of oxidation-assisted crack growth has also been carried out at elevated temperature from the finite
\end{abstract}


element analyses of oxygen diffusion near a fatigue crack tip. A failure curve for crack growth has been constructed based on the consideration of both oxygen concentration and accumulated inelastic strain near the crack tip. The predictions from the fatigue-oxidation failure curve compared well with the experimental results for triangular and dwell loading waveforms, with significant improvement achieved over those predicted from the viscoplastic model alone.

Keywords: Oxygen diffusion; Finite element; Visco and crystal plasticity; Failure curve; Crack growth.

\section{Introduction}

Nickel-based superalloys are favoured for disc rotors in high pressure compressor and turbine of aero-engines due to their exceptional mechanical properties at high temperature. Oxidation damage, when combined with fatigue, is a major concern for disc rotors exposed to arduous gas environment for prolonged periods. Evidence of oxidation in nickel alloys has been presented for both smooth and cracked specimens with appreciable oxide layers built on free surfaces and at internal grain boundaries [1-8]. Oxidation results in reduced fatigue life by promoting early cracking of surface oxide scales followed by the dominantly intergranular cracking at accelerated growth rates $[4,5,9]$. A number of mechanisms have been proposed for oxidation induced damage, including formation of both external and internal brittle oxides (Ni, $\mathrm{Nb}, \mathrm{Al}, \mathrm{Cr})[4,5,9,10]$, vacancy injection [11], gas bubble formation $\left(\mathrm{CO}\right.$ or $\left.\mathrm{CO}_{2}\right)$ [1] and releasing of embrittling alloy elements [12] at the grain boundaries.

Mechanical deformation was shown to play a significant role in oxidation and corrosion damage for nickel and its alloys [13-18]. For instance, Moulin et al. [13] studied the influence of external 
mechanical loading on oxygen diffusion during nickel oxidation. Oxygen enrichment was observed in the oxide scale under mechanical loading and the ingress of oxygen in the substrate beneath the oxide scale became easier in the presence of a constant tensile load (creep). Berger et al. [14, 15] reported that the application of a constant load induced multiple cracks at the surface of nickel oxide scale and an increase of oxygen diffusivity by two orders of magnitude, although the enhancement of oxygen diffusivity decreased with the further increase of load level. The oxidation kinetics curves gained by thermogravimetric analysis indicated that the oxidation rate of pure nickel was accelerated by both tensile and compressive external stress [16]. A study of cast nickel superalloy IN100 showed that matrix oxidation was strongly enhanced by fatigue cycling [17]. Effects of applied tensile stress on the growth kinetics of oxide scales were also studied for Ni-20Cr alloys [2], where the internal oxidation and the oxide layers were shown to be much thicker than that formed without load. This was also the case for internal nitridation of nickel alloy Inconel 718 under mechanical stress [18]. Stress-enhanced oxidation was also found for other metallic materials such as Cr-Mo steel, where both oxide layer and penetration of oxide along preferential paths (e.g., cracks, grain boundaries) increased significantly under strain-controlled low cycle fatigue [19, 20].

Alloy RR1000 studied here is one of the new generation polycrystalline nickel alloys, developed at Rolls-Royce plc, to meet the demands for higher overall pressure ratios, compressor discharge temperatures and rotational speeds for the latest aero-engines. The material was produced through a powder metallurgy route and has a fine grain microstructure, with an average grain size of $\sim 5 \mu \mathrm{m}$ [21]. Fatigue, creep and material constitutive behaviour of RR1000 at high temperatures have been extensively studied at Portsmouth [22-27]. Oxidation damage of alloy RR1000 was investigated by Encinas-Oropesa et al. [28] at temperatures between $700^{\circ} \mathrm{C}$ and $800^{\circ} \mathrm{C}$ from thermogravimetric analyses of small disc samples, where the oxide scale rich in $\mathrm{Cr}$ and $\mathrm{Ti}$ had been found to grow in a 
parabolic dependence with time. FIB examinations of oxidised samples for RR1000 revealed the formation of recrystallised grains and voids beneath the oxide scales [28]. The oxidation-linked microstructure damage becomes more significant with the increase of testing temperature. The thickness of oxide scale and the depth of internal damage, exemplified as voids along grain boundaries, are more than tripled at $800^{\circ} \mathrm{C}$ when compared to those at $700^{\circ} \mathrm{C}$. Oxide particles can also be observed on the surface of those internal micro-voids from the FIB images [28]. Recently, Karabela et al. [29, 30] investigated the influence of fatigue on oxidation damage of alloy RR1000. The results suggest that fatigue does not appear to change the nature of oxidation damage but tends to enhance the extent of oxidation damage at temperatures of $750^{\circ} \mathrm{C}$ and $800^{\circ} \mathrm{C}$. The influence of cyclic stress on oxidation damage appears to be insignificant at lower temperatures though. In addition, crack growth tests for alloy RR1000 at elevated temperature showed an increased crack growth rate with the increase of a dwell period imposed at the maximum load and the decrease of loading frequency due to the detrimental role of oxidation $[24,31]$.

Oxidation-assisted crack propagation in nickel alloys is a result of oxygen diffusion into a local area with increasing tensile stresses, such as crack tips [32-34]. Oxygen, by itself or through chemical reaction, attacks the grain boundaries by lowering boundary cohesion and prompts accelerated intergranular cracking [32-34]. The diffusion process is facilitated by high tensile stresses near the crack tip [32-35], especially for superimposed dwell periods at maximum load where the crack tip is fully open and experiences sustained high tensile stresses. Generally, computational simulations of oxygen diffusion $[33,34,36-37]$ are based on Fick's first and second laws, where the effect of stress on oxygen diffusion is assumed to be controlled by the gradient of hydrostatic stress [38-41]. In this case, diffusion of oxygen within the material is controlled by two essential parameters, namely, the oxygen diffusivity and the pressure factor [33, 34, 36-37]. This approach has been applied to study 
the hydrogen $[35,41]$ and oxygen $[36,37]$ embrittlement of engineering materials under mechanical loading conditions, including the prediction of crack growth under fatigue-oxidation conditions. Furthermore, simulation of stress-driven oxygen diffusion has been carried out for alloy RR1000 at grain level, where the material micro-structure was explicitly considered [42]. The heterogeneous deformation at grain level due to the orientation mismatch between neighbouring grains introduced a large local stress gradient, and was shown to have significant influence on the oxygen diffusion process along the grain boundaries [42]. However, the diffusion parameters used in [42] were estimated from the surface oxide scale growth rather than the depth of internal oxidation. Modelling of oxygen diffusion coupled with viscoplasticity has also been developed to study oxidation-assisted crack growth for alloy RR1000 [37]. A failure envelope, expressed in terms of oxygen concentration and accumulated inelastic strain, has been constructed and successfully utilised to predict crack growth rates in a CT specimen under fatigue-oxidation conditions [37]. However, the values of the two essential diffusion parameters, namely the oxygen diffusivity and pressure factor, were assumed due to the lack of experimental data.

The objective of this work is to further investigate the effects of fatigue and temperature on oxidation damage of alloy RR1000, with a focus on oxygen diffusion and associated crack growth. FIB microscopic analyses of waisted specimens, tested under cyclic loads in laboratory air at $700^{\circ} \mathrm{C}$, $750^{\circ} \mathrm{C}$ and $800^{\circ} \mathrm{C}$, were carried out to examine the effects of cyclic stress on oxygen penetration. Oxygen diffusion along grain boundaries was modelled for a waisted specimen, and the diffusion parameters were calibrated based on the FIB measurements of internal oxygen penetration. Using the obtained diffusion parameters, we also simulated the process of oxygen diffusion into a crack tip and its subsequent effect on crack growth. Based on the consideration of both oxygen concentration and accumulated inelastic strain near the crack tip, a failure curve was constructed and subsequently 
utilized to predict crack growth rates under fatigue-oxidation conditions for selected loading frequencies and dwell periods. The results were compared against the experimental results $[16,32]$ and those predicted from the viscoplastic model.

\section{Microscopy analyses}

\subsection{Material}

The alloy under investigation is fine grain RR1000, produced through a powder metallurgy route by Rolls-Royce for disc rotor applications in the latest aero-engines. The chemical composition of RR1000 is $18.5 \mathrm{Co}-15 \mathrm{Cr}-5 \mathrm{Mo}-3.6 \mathrm{Ti}-3 \mathrm{Al}-2 \mathrm{Ta}-0.5 \mathrm{Hf}-0.03 \mathrm{C}-0.02 \mathrm{~B}-0.06 \mathrm{Zr}$ and balance $\mathrm{Ni}$ in weight percentage. The alloy has a two-phase microstructure consisting of $\gamma$ matrix and strengthening $\gamma^{\prime}$ precipitates $\mathrm{Ni}_{3}(\mathrm{Al}, \mathrm{Ti}, \mathrm{Ta})$ which are largely responsible for the elevated temperature strength of the alloy. An average grain size of $\sim 5 \mu \mathrm{m}$ was determined from an EBSD (Electron Backscatter Diffraction) analysis [21]. The yield stress of the material is $1030 \mathrm{MPa}(0.2 \%$ proof stress $)$ at $650^{\circ} \mathrm{C}$.

\subsection{Specimen}

Waisted specimens, as shown in Fig.1, were provided by Rolls-Royce for fatigue testing in air at $700^{\circ} \mathrm{C}, 750^{\circ} \mathrm{C}$ and $800^{\circ} \mathrm{C}$ under a triangular loading waveform. The specimen has a diameter of 4.4 $\mathrm{mm}$ and $18 \mathrm{~mm}$ for the narrowest section and the section at the ends, respectively, and a length of 94 $\mathrm{mm}$. Under fatigue loading, this will produce variable stress levels across the specimen length. For $700^{\circ} \mathrm{C}$ and $750^{\circ} \mathrm{C}$, a load of $10 \mathrm{kN}$ was applied, with a load ratio of $\mathrm{R}=0.1$ and a loading frequency $\mathrm{f}$ $=0.25 \mathrm{~Hz}$. For $800^{\circ} \mathrm{C}$, the load was reduced to $8 \mathrm{kN}$, considering the reduced mechanical properties at such a high temperature; while the load ratio and loading frequency remain unchanged $(R=0.1$ and $\mathrm{f}=0.25 \mathrm{~Hz}$ ). At $700^{\circ} \mathrm{C}$, the specimen was loaded for 176,763 cycles, approximately 196 hours, and survived the test duration without failure, while fatigue failure occurred in specimens tested at 
$750^{\circ} \mathrm{C}$ and $800^{\circ} \mathrm{C}$ with complete fracture at the narrowest section. The fatigue life is 174,392 cycles (194h) at $750^{\circ} \mathrm{C}$ and 33,473 cycles $(38 \mathrm{~h})$ at $800^{\circ} \mathrm{C}$, indicating a drastic reduction of fatigue resistance at temperatures up to $800^{\circ} \mathrm{C}$.

\subsection{FIB analyses}

FIB system was used to cut trenches on the specimen surface to reveal the nature of the oxidised surface after the fatigue tests. The equipment is an FEI Strata 200xP FIB with a fine gallium $\left(\mathrm{Ga}^{+}\right)$ beam. The specimen was mounted onto a special grip and then placed inside the FIB chamber where vacuum conditions apply. An area of interest, with a dimension of $25 \mu \mathrm{m} \times 2 \mu \mathrm{m}$, was selected and a layer of platinum $(\mathrm{Pt})$ deposition was applied on the selected surface to avoid both contamination and stray sputter damage during the FIB milling operations. The cutting operation using the $\mathrm{Ga}^{+}$ beam was initially in coarse steps, followed by finer steps to produce one flat side to the trench [28]. FIB images were produced via detected back scattered electrons that resulted from bombardment of the sample using low power $\mathrm{Ga}^{+}$ion beam, which scans the flat side of the trench.

For waisted specimen, three locations on each specimen, as illustrated by "A", "B", "C" in Fig.1, were chosen to examine the influence of cyclic stress level on oxidation damage. Point A is located at the narrowest section, which has the highest stress level, while points $B$ and $C$ are $15 \mathrm{~mm}$ and $30 \mathrm{~mm}$, respectively, away from the point $\mathrm{A}$ and have reduced stress levels due to the increased crosssectional areas. Specifically, under the load of $10 \mathrm{kN}$, the stress level is $670 \mathrm{MPa}, 350 \mathrm{MPa}$ and $100 \mathrm{MPa}$, i.e., $65 \%, 34 \%$ and $10 \%$ of $0.2 \%$ proof stress of the material at $650^{\circ} \mathrm{C}$, at point $\mathrm{A}, \mathrm{B}$ and $\mathrm{C}$, respectively.

\section{Modelling of oxygen diffusion}




\subsection{Governing equations}

Here we are concerned with the diffusive transport of oxygen into the material, which can be modelled as [38-40]:

$$
\frac{\partial C}{\partial t}=\nabla(D \nabla C-D C M \nabla P)
$$

where $C$ is the concentration of the solute, $t$ the time, $\nabla$ the gradient, $D$ the oxygen diffusivity, $P$ the hydrostatic stress (pressure) and $M$ the pressure factor. The constitutive law (1) has been used to account for the influence of mechanical stress on mass transport [33-41]. The gradient of hydrostatic stress (or pressure) is regarded as the driving force for stress-assisted diffusion process. In the absence of pressure stress effects, i.e., the pressure factor $M=0$, the formulation is reduced to natural diffusion.

\subsection{Oxygen flux boundary conditions}

The boundary condition for oxygen diffusion from the surface into the material follows the parabolic law, which is determined from oxidation kinetics study [28]. The oxidation kinetics of RR1000 has been studied in [28] for temperature from $700^{\circ} \mathrm{C}$ to $800^{\circ} \mathrm{C}$. The mass gain per unit area due to oxidation is a parabolic function of time and can be expressed as

$$
(\Delta W)^{2}=\kappa t
$$

where $\Delta \mathrm{W}$ is the mass gain, $\kappa$ the parabolic oxidation growth rate and $t$ the time.

The flux of oxygen into the material at the surface can be derived by performing a differentiation with respect to time for equation (2), which gives:

$$
J_{O_{2}}=\frac{d(\Delta W)}{d t}=\frac{1}{2} \sqrt{\frac{\kappa}{t}}
$$


The above flux boundary condition has been applied in the diffusion analyses, where the value of $\kappa$ is given in [28] for RR1000.

\section{Visco-plasticity and crystal plasticity models}

\subsection{Viscoplasticity}

The global material behaviour is described by the unified constitutive equations developed by Chaboche [43], where both isotropic $(R)$ and kinematic $(\boldsymbol{\alpha})$ hardening variables are considered during the transient and saturated stages of cyclic response. A power-law relationship is adopted for the viscopotential and the viscoplastic strain rate $\dot{\boldsymbol{\varepsilon}}_{p}$ is expressed as [43]:

$$
\dot{\boldsymbol{\varepsilon}}_{p}=\left\langle\frac{f}{Z}\right\rangle^{n} \frac{\partial f}{\partial \boldsymbol{\sigma}}
$$

where $f$ is the von Mises yield function, $Z$ and $n$ are material constants, and the brackets imply that

$$
\langle x\rangle=x \text { for } x>0 \text { and }\langle x\rangle=0 \text { for } x \leq 0 .
$$

According to the von Mises yield criterion, the yield function $f$ is defined as

$$
f\left(\sigma, \alpha, R, k_{0}\right)=J(\sigma-\alpha)-R-k_{0} \leq 0
$$

where $R$ is the isotropic hardening variable and $k_{0}$ is the initial value of the radius of the yield surface. $J$ denotes the von Mises distance in the deviatoric stress space:

$$
J(\sigma-\alpha)=\sqrt{\frac{3}{2}\left(\sigma^{\prime}-\alpha^{\prime}\right):\left(\sigma^{\prime}-\alpha^{\prime}\right)}
$$

where $\sigma^{\prime}$ and $\boldsymbol{\alpha}^{\prime}$ are the deviators of $\sigma$ and $\boldsymbol{\alpha}$, represents the inner product of two tensors. Plastic flow occurs under the condition $f=0$ and $\frac{\partial f}{\partial \boldsymbol{\sigma}}: \dot{\boldsymbol{\sigma}}>0$. For this model, the motion of yield surface 
continues to hold but the stress in excess of the yielding stress is now admissible and often termed as “overstress".

The evolution of the kinematic stress tensor $\boldsymbol{\alpha}$ and the isotropic stress $R$ follow [43]:

$$
\left\{\begin{array}{l}
\dot{\boldsymbol{\alpha}}=\dot{\boldsymbol{\alpha}}_{1}+\dot{\boldsymbol{\alpha}}_{2} \\
\dot{\boldsymbol{\alpha}}_{1}=C_{1}\left(a_{1} \dot{\boldsymbol{\varepsilon}}_{p}-\alpha_{1} \dot{p}\right) \\
\dot{\boldsymbol{\alpha}}_{2}=C_{2}\left(a_{2} \dot{\boldsymbol{\varepsilon}}_{p}-\boldsymbol{\alpha}_{2} \dot{p}\right)
\end{array} \quad \text { and } \quad \dot{R}=b(Q-R) \dot{p}\right.
$$

where $C_{1}, a_{1}, C_{2}, a_{2}, b$ and $Q$ are six material and temperature dependent constants which determine the shape and amplitude of the stress-strain loops during the transient and saturated stage of cyclic response, and $\dot{p}$ is the accumulated inelastic strain rate defined by

$$
\dot{p}=\left\langle\frac{f}{Z}\right\rangle^{n}=\sqrt{\frac{2}{3} d \dot{\boldsymbol{\varepsilon}}_{p}: d \dot{\boldsymbol{\varepsilon}}_{p}} .
$$

\subsection{Crystal plasticity}

The material deformation at grain level was described by the crystal plasticity theory, where the flow rule is expressed in terms of slip resistance $\left(S^{\alpha}\right)$ and back stress $\left(B^{\alpha}\right)[44]$,

$$
\dot{\gamma}_{\alpha}=\dot{\gamma}_{0} \exp \left[\frac{-F_{0}}{k \theta}\left\langle 1-\left\langle\frac{\left|\tau^{\alpha}-B^{\alpha}\right|-S^{\alpha} \mu / \mu_{0}}{\hat{\tau}_{0} \mu / \mu_{0}}\right\rangle^{p_{0}}\right\rangle^{q_{0}}\right] \operatorname{sgn}\left(\tau^{\alpha}-B^{\alpha}\right)
$$

where $k$ is the Boltzmann constant, $\tau^{\alpha}$ is the resolved shear stress on the slip system $\alpha, \theta$ the absolute temperature, $\mu$ and $\mu_{0}$ the shear moduli at $\theta$ and 0 Kelvin, respectively, and $\mathrm{F}_{0}, \hat{\tau}_{0}, p_{0}, q_{0}$ and $\dot{\gamma}_{0}$ are material constants. 
The two internal variables, the slip resistance in each slip system, $S^{\alpha}$, and the back stress, $B^{\alpha}$, are introduced at the slip system level, which represent the state associated with the current dislocation network. The slip resistance on a generic slip system, associated with the dislocation density along that slip system (i.e., self-hardening), is assumed to evolve according to the following relation, starting at an initial value of $S_{0}[45]$,

$$
\dot{S}^{\alpha}=\left[h_{S}-d_{D}\left(S^{\alpha}-S_{0}^{\alpha}\right)\right]\left|\dot{\gamma}^{\alpha}\right|
$$

where the first and second terms are static and dynamic recovery terms associated with the material constants $h_{\mathrm{S}}$ and $d_{\mathrm{D}}$, respectively.

The back stress is representative of the internal stress state arising due to dislocations bowing between obstacles which can be either precipitates or other dislocations. The back stress evolves according to a standard hardening-dynamic recovery format [45],

$$
\dot{B}^{\alpha}=h_{B} \dot{\gamma}^{\alpha}-r_{D} B^{\alpha}\left|\dot{\gamma}_{\alpha}\right|
$$

where $h_{\mathrm{B}}$ is a hardening constant, and $r_{\mathrm{D}}$ is a dynamic recovery function which introduces the inherent dependency between the slip resistance and back stress and may be expressed as [45],

$$
r_{D}=\frac{h_{B} \mu_{0}}{S^{\alpha}}\left\{\frac{\mu_{0}^{\prime}}{f_{c} \lambda}-\mu\right\}^{-1}
$$

where $f_{\mathrm{c}}$ is a coupling parameter between the internal slip variables and $\mu_{0}^{\prime}$ the local slip shear modulus at 0 Kelvin.

\subsection{Model parameters and UMAT}

Both the viscoplasticity and crystal plasticity formulation were implemented numerically into the finite element (FE) code ABAQUS [46] via a user-defined material subroutine (UMAT), where the 
fully implicit (Euler backward) integration algorithm was adopted [27, 47, 48]. Values of the viscoplasticity model parameters (Table 1) were optimized from the uniaxial experimental data of Alloy RR1000 at $650^{\circ} \mathrm{C}[25,49]$, which fit very well with the measured viscoplastic material response for a range of strain-controlled loading conditions [25, 49].

For crystal plasticity, a three-dimensional representative volume element (Figure 2a), consisting of randomly oriented grains, was built for the finite element analyses under periodic boundary constraints $[50,51]$. Strain-controlled cyclic test data at $650^{\circ} \mathrm{C}$ were used to determine the model parameters from a fitting process, where three loading rates were considered. The fitted parameters are listed in Table 2. Other fitted parameters include the coefficient $\lambda=0.85$ and the shear modulus at 0 Kelvin $\mu_{0}=162 \mathrm{GPa}$. Anisotropic stiffness constants were taken as $C_{11}=146.2 \mathrm{GPa}, C_{12}=62.6$ GPa and $C_{44}=117.6 \mathrm{GPa}$, which give a global Young's modulus of $190 \mathrm{GPa}$ for alloy RR1000 at $650^{\circ} \mathrm{C}$ and matches the experimental measurement [49]. Model simulations are in good agreement with the experimental results for stress-strain loops, cyclic hardening behaviour and stress relaxation during the strain hold periods $[25,49]$. For demonstration, comparison of simulation and test results is shown in Figure $2 \mathrm{~b}$ for the stress-strain loop of the first cycle with a strain rate $0.05 \% / \mathrm{s}$ and a strain range $2 \%$.

\section{Finite element analyses}

\subsection{Waisted specimen model}

To study the effects of mechanical stress on oxygen diffusion, a quarter of the waisted specimen geometry was considered under fatigue loading conditions. The finite element global model, as shown in Fig.3(a), consisted of first-order elements with full integration [46]; while the submodel consisted of 150 grains with randomly assigned orientation (Fig.3 (b) and (c)). The submodel was 
meshed into 1,450 four-node first-order elements with full integration using ABAQUS [46]. The element size was about $1 \mu \mathrm{m}$, quarter of the average grain size of the material. Specifically, each grain has about 20 to 30 finite elements. Grain boundaries were meshed into one-dimensional diffusion elements [46], which share the same nodes with the bulk elements. On the right edge, the oxygen flux boundary condition given by Equation (3), was applied to each node to represent the surface oxidation process.

To solve the fatigue-oxidation problem, a sequentially coupled mechanical-diffusion analysis was performed to consider the dependence of oxygen diffusion on the stress state. The mechanical analyses for the global model and sub model were carried out first, with the history of hydrostatic stress for each node stored in the ABAQUS [46] output files. Crystal plasticity model was used for submodel FE analyses, while elastic analysis was used for the global model analyses as the applied load is below the yield level $[29,30]$. During the diffusion analysis, the output files were used as inputs to include the effect of hydrostatic stress gradient on oxygen diffusion. Oxygen diffusion was assumed to occur along the grain boundaries only, consistent with experimental observations. Oxygen diffusion in bulk material was excluded in the diffusion analyses by assigning negligible diffusivity to the bulk elements.

\subsection{CT specimen model}

A standard compact tension (CT) specimen, which has the same geometry as that used for the crack growth testing by Dalby and Tong [24], was considered for the finite element study of crack-tip oxygen diffusion and crack growth. The specimen (width $\mathrm{W}=26 \mathrm{~mm}$ and height $\mathrm{H}=15.6 \mathrm{~mm}$ ) was meshed into two-dimensional first-order elements. As shown in Figure 4, refined mesh (4-node, full integration) was used for the crack tip area, while slightly coarse mesh (3-node, full integration) was 
used outside the crack tip area in order to save the computation time. At the crack tip, the element has a size of $6.35 \mu \mathrm{m}$, which is slightly over the average grain size of the material [21]. The crack length was chosen to be $\mathrm{a}=13 \mathrm{~mm}$, half of the specimen width $(\mathrm{a} / \mathrm{W}=0.5)$. All $\mathrm{FE}$ analyses were carried out with a constant stress intensity factor range $\Delta K$ and a ratio of $R=0.1$. The load was applied to the specimen through a rigid pin modelled as a pair of contact surfaces in ABAQUS. For pure fatigue loading, a triangular waveform was used and frequencies varied from 0.001 to $2.5 \mathrm{~Hz}$. For dwell loading, a trapezoidal waveform was used with a 1-x-1-1 pattern, where $\mathrm{x}$ is the dwell time and varies from 1 to 1000s [24]. Viscoplasticity model was used for mechanical FE analyses, followed by the oxygen diffusion analysis as described above. In the present work, a sharp crack was modelled without the consideration of crack blunting effect. Introducing crack blunting might cause a change in stress distribution near the crack tip and subsequently influence oxygen diffusion process near the crack tip.

\section{Microscopy characterisation and measurement}

\subsection{FIB examinations}

FIB analyses were performed to examine the oxidation damage for the tested specimens and the secondary ion images taken for position "A" are shown in Figs.5a, b and c for the three temperatures, where the bright areas below the specimen surface indicate the oxides within the material. At $700^{\circ} \mathrm{C}$, oxidation is limited to the surface area of the specimen. The oxide scale above the surface has a thickness of up to $0.8 \mu \mathrm{m}$ and the depth of internal oxidation (below the surface and into the material) is measured up to $1.0 \mu \mathrm{m}$. In this paper, the thickness of oxide scale was measured as the distance between the identified specimen surface and the surface of the oxide scale; while the depth of internal oxidation was measured as the distance between the identified specimen surface and the tips of internal oxides. 
At $750^{\circ} \mathrm{C}$ and $800^{\circ} \mathrm{C}$, as shown in Figs. $5 \mathrm{~b}$ and $\mathrm{c}$, the specimens showed more severe oxidation damage when compared to that at $700^{\circ} \mathrm{C}$, with a thicker oxide scale and a deeper oxide into the specimen. At $750^{\circ} \mathrm{C}$, the thickness of oxide scale is measured up to $1.6 \mu \mathrm{m}$ (Fig.5b), almost twice as much as that for the $700^{\circ} \mathrm{C}$ specimen. The depth of internal oxidation measured from the obtained FIB image is up to $2.5 \mu \mathrm{m}$, which is more than doubled when compared to that for the $700^{\circ} \mathrm{C}$ specimen. At $800^{\circ} \mathrm{C}$, the thickness of oxide scale and the depth of internal oxidation have values up to $1.7 \mu \mathrm{m}$ and $7.0 \mu \mathrm{m}$, respectively (Fig.5c).

\subsection{Effect of stress level on oxidation penetration}

To examine the effects of cyclic stress level on oxidation damage, FIB ion images, taken at the three locations A, B and C, were compared. The same types of oxidation damage were observed at all three locations, i.e., the oxide scales built on the surface and the internal oxides along the grain boundaries. This can be seen from the FIB ion images of oxidation damage presented in Fig.6 for position $\mathrm{B}$ and $\mathrm{C}$ at $800^{\circ} \mathrm{C}$. Furthermore, the maximum depth of internal oxidation were measured for the three locations and presented in Fig. 7 for $700^{\circ} \mathrm{C}, 750^{\circ} \mathrm{C}$ and $800^{\circ} \mathrm{C}$. It can be seen that, at $750^{\circ} \mathrm{C}$ and $800^{\circ} \mathrm{C}$, the cyclic stress has a notable influence on the severity of the internal oxidation damage. The maximum depth of internal damage increased with the increase of the stress level. At $800^{\circ} \mathrm{C}$, the extent of the maximum internal damage at the highest stress area (Point A) nearly doubled that at the lowest stress area (Point C), with a measured difference of $3.8 \mu \mathrm{m}$. At $750^{\circ} \mathrm{C}$, the maximum depth of internal oxidation damage at Point $\mathrm{A}$ is $0.5 \mu \mathrm{m}$ more than that at Point $\mathrm{C}$. However, at $700^{\circ} \mathrm{C}$, the effect of cyclic stress on oxidation damage seems to be insignificant, as shown in Fig.7. This might be due to the relatively low level of oxidation kinetics at this temperature [28]. 
In Fig.7, we reported the maximum depth of internal oxidation rather than an average, as we are particularly interested in the fastest oxygen diffusion path. However, it should be noted that the FIB images (e.g. Figs. 5 and 6) are two-dimensional projections, and the appearance of internal oxidation in the FIB images depends on the location as well as the direction of FIB milling. Consequently, the measurements may vary if a different FIB position or a different milling direction is selected.

\section{Simulation of oxygen diffusion}

\subsection{Oxygen diffusivity}

Modelling of natural diffusion of oxygen has been carried out first, where the oxygen diffusivity was calculated using the depth of oxygen penetration measured by FIB. The diffusivity (or diffusion coefficient) was calculated based on [19]:

$$
X^{2}=D t
$$

where $\mathrm{D}$ is the diffusivity, $\mathrm{X}$ is the maximum depth of internal oxidation measured from the FIB analysis in Section 3 (position $C$ for the waisted specimen) and $t$ is the time. The obtained values at $700^{\circ} \mathrm{C}, 750^{\circ} \mathrm{C}$ and $800^{\circ} \mathrm{C}$ are given in Table 3, where the value for $650^{\circ} \mathrm{C}$ was extrapolated using an Arrhenius equation.

\subsection{Effect of mechanical stress on oxygen diffusion}

To study the effects of mechanical stress on oxygen penetration, finite element analyses of the global model and submodel were first carried out for $800^{\circ} \mathrm{C}$ under fatigue loading condition using elasticity and crystal plasticity material model, respectively. Following the mechanical deformation analyses, diffusion analyses were carried out for a given pressure factor of $0.3 \mathrm{MPa}^{-1}$, where the stress-driven oxygen diffusion was accounted for through Equation (1). Contour plot of the oxygen concentration 
is shown in Figure 8 for $800^{\circ} \mathrm{C}$, where fatigue loading tends to induce a non-uniform distribution of oxygen concentration (Figure 8(b)) along the grain boundaries when compared to the case for natural diffusion (Figure 8(a)). As illustrated in Figure 8, the maximum depth of oxygen penetration into the material is found to be $\delta=7.313 \mu \mathrm{m}$, which is twice more than that for natural diffusion $\left(\delta_{0}=\right.$ $3.207 \mu \mathrm{m})$.

Although there are no direct experimental results available yet, our numerical model has demonstrated the effect of stress on the diffusion of oxygen along the grain boundaries (Fig.8). This is also supported by our FIB measurements of internal oxidation damage which occurs mainly along the grain boundaries. It is believed that the different degree of internal oxidation damage at points A, $\mathrm{B}$ and $\mathrm{C}$ is due to the different levels of stress. Plastic strain may also play a role but regarded as minor since the applied load is well below the yield level (Section 2.3).

\subsection{Determination of pressure factor}

According to Equation (1), two parameters (diffusivity and pressure factor) are required to model fatigue-assisted oxygen diffusion. Diffusivity has been calculated from the FIB measurements of the maximum depth of internal oxidation and given in Table 3. To work out the pressure factor, FE analyses have been carried out to obtain the maximum depth of oxygen penetration for selected pressure factor values, and the results are shown Figures $9 \mathrm{a}$ and $\mathrm{b}$ for $750^{\circ} \mathrm{C}$ and $800^{\circ} \mathrm{C}$, respectively. For both temperatures, the maximum oxygen penetration depth $(\delta)$ is normalised against that $\left(\delta_{0}\right)$ for natural diffusion.

At $750^{\circ} \mathrm{C}$, the maximum depth of oxygen penetration follows a linear trend with the increase of the pressure factor (Figure 9a). While, at $800^{\circ} \mathrm{C}$, the maximum depth of oxygen penetration has a linear 
trend for pressure factor up to a value of $0.17 \mathrm{MPa}^{-1}$, then followed by a sharp increase (Figure 9b). According to the FIB measurements, the maximum oxygen penetration depth has a normalised value $\left(\delta / \delta_{0}\right)$ of 1.209 for $750^{\circ} \mathrm{C}$ and 2.012 for $800^{\circ} \mathrm{C}$, which correspond to pressure factor values of $0.068 \mathrm{MPa}^{-1}$ and $0.188 \mathrm{MPa}^{-1}$ for $750^{\circ} \mathrm{C}$ and $800^{\circ} \mathrm{C}$ respectively, as indicated in Figure $9 \mathrm{a}$ and $\mathrm{b}$. The obtained pressure factor is given in Table 4 , where the values for $650^{\circ} \mathrm{C}$ and $700^{\circ} \mathrm{C}$ were extrapolated using an Arrhenius equation.

\section{Fracture criterion and prediction of crack growth under fatigue-oxidation conditions}

\subsection{Failure curve}

Here we are concerned with the diffusive transport of oxygen into the crack tip under the influence of a mechanical loading field. Although the availability of oxygen may vary in the vicinity of the crack tip, as does the oxygen partial pressure, the oxygen intake on the crack surface was assumed to be uniform and follows the Equation (3). The diffusion parameters were already obtained from the FE analyses performed on the waisted specimen and, at $650^{\circ} \mathrm{C}$, they are found to be: $\kappa=1.67 \times 10^{-}$ ${ }^{13} \mathrm{mg}^{2} / \mathrm{mm}^{4} / \mathrm{s}$ for the parabolic rate constant, $\mathrm{D}=1.085 \times 10^{-13} \mathrm{~mm}^{2} / \mathrm{s}$ for the diffusivity and $\mathrm{M}=$ $1.585 \times 10^{-3} \mathrm{~mm}^{2} / \mathrm{N}$ for pressure factor.

In order to predict the crack growth rates under fatigue-oxidation conditions, it is necessary to establish an appropriate criterion to account for the contributions from both mechanical deformation and oxidation. Here, two parameters, namely the accumulated inelastic strain and oxygen concentration, were used to represent the viscoplastic deformation and the oxidation effect, respectively. The accumulated inelastic strain, highly localised to the crack tip [27, 37], has been successfully used to predict crack growth rate in vacuum (without oxidation) [52, 53]. The idea proposed here is to use the two parameters to construct a failure curve from which crack growth 
prediction under fatigue-oxidation may be made. Experimental crack growth data for selected loading frequencies at $\Delta \mathrm{K}=30 \mathrm{MPa} \sqrt{\mathrm{m}}_{\mathrm{m}}[24,31]$ were utilised to determine the number of cycles required to grow the crack in the FE model. Specifically, the number of cycles was calculated by dividing the near-tip element size $(6.35 \mu \mathrm{m})$ with the measured crack growth rate. FE analyses were then carried out for the calculated number of cycles, i.e., just before the crack grows into the next element, and the values of the two parameters were extracted. The extracted values of the two parameters were then plotted against each other to obtain a failure curve. The results are presented in Figure 10, where all the data seem to form a failure curve, which indicates a "safe zone" outside which the crack will grow.

Crack growth criterion proposed in the current work is essentially a strain-based approach, which has been widely used for the prediction of viscoplastic failures such as creep [54-56]. The strains local to a crack tip are of multiaxial nature such that an accumulated strain, which accounts for all strain components, is often adopted as a damage parameter [54-57]. This parameter, combined with oxygen concentration, is also used in the present work. Furthermore, the choice of the accumulated plastic strain seems justified in that, under fatigue loadings, the reversed deformation during unloading is accounted for as well as that during loading. For alloy RR1000, which has superior high-temperature mechanical properties and toughness, fatigue deformation at $650^{\circ} \mathrm{C}$ is most likely to be associated with the accumulated viscoplastic deformation. As stress-based failure criterion is generally responsible for brittle fracture, and consequently the role of stress was not considered in the current work.

\subsection{Prediction of crack growth}


Using the failure curve constructed above, crack growth rates in a CT specimen at $650^{\circ} \mathrm{C}$ can be predicted from the finite element analyses for selected loading frequencies and dwell time at $\Delta \mathrm{K}=30 \mathrm{MPa} \sqrt{\mathrm{m}}_{\mathrm{m}}$. During the analyses, the accumulated inelastic strain and the oxygen concentration over the characteristic distance $d^{*}=6.35 \mu \mathrm{m}$ ahead of the crack tip were recorded against the number of cycles. The results were then used to obtain the number of cycles for the crack to grow, i.e., when the combination of the accumulated inelastic strain and the oxygen concentration reached the failure curve. The average crack growth rate was then calculated by dividing the characteristic distance with the number of cycles.

The predicted effects of loading frequency on crack growth rates is shown in Figure 11 for $\Delta K=30$ and $40 \mathrm{MPa} \sqrt{\mathrm{m}}_{\mathrm{m}}$, in comparison with the test data for $\mathrm{CT}$ specimens at $650^{\circ} \mathrm{C}[24,31]$. For the predictions based on fatigue-oxidation failure curve, an excellent agreement was achieved for all loading frequencies.

The predicted effects of dwell time on crack growth rates is shown in Figure 12 for $\Delta \mathrm{K}=30$ and 40 $\mathrm{MPa} \sqrt{\mathrm{m}}_{\mathrm{m}}$, in a direct comparison with test data for $\mathrm{CT}$ specimens at $650^{\circ} \mathrm{C}[24,31]$. The predictions from accumulated inelastic strain show increased deviation from the experimental data as the dwell period is increased, especially when a dwell period is over 60 seconds. Again, this difference is much reduced when the fatigue-oxidation failure curve was used for the prediction.

\section{Discussion}

In the current work, internal oxidation damage was particularly identified for alloy RR1000 from the FIB secondary ion imaging (Figs.5 and 6). The results showed that, in addition to the outwards diffusion of alloy elements (e.g., $\mathrm{Cr}, \mathrm{Ti}, \mathrm{Ni}$ ) to form surface oxides, oxygen also simultaneously 
transports into the material, through the porous oxide scale and internal voids along the grain boundaries, and chemically reacts with the alloy elements to form internal oxide particles. Internal oxide particles are considered to be a mixture of $\mathrm{TiO}_{2}$ and $\mathrm{Al}_{2} \mathrm{O}_{3}[28,58,59]$. Internal oxidation of nickel-base alloys could further enhance oxygen diffusion process due to the presence of incoherent interface between the internal oxides particles and the alloy matrix as well as the injection of vacancies into the alloy by the growing surface oxide scales [60]. Oxygen penetration and associated internal oxidation, especially along grain boundaries, may lead to critical embrittlement of the material and results in significantly shortened fatigue life. Imposed fatigue loading tends to enhance the depth of internal oxidation, especially for relatively high temperatures. At $800^{\circ} \mathrm{C}$, the extent of the internal damage at the highest stress area (Point A) nearly doubled that at the lowest stress area (Point C). At $750^{\circ} \mathrm{C}$, the extent of the internal oxidation damage at Point $\mathrm{A}$ is $50 \%$ more than that at Point C.

Simulation of internal oxidation has been carried out from oxygen diffusion analyses based on Fick's first and second laws. In the absence of mechanical stress, oxygen diffusion purely depends on the temperature, which is consistent with the experimental study of oxidation of alloy RR1000 [28]. For modelling of stress-assisted oxygen diffusion, a sequential coupling between the mechanical deformation and oxygen diffusion was adopted to include the effect of stress fields on oxygen diffusion process $[34,36]$. Figure 13 shows the contour plot of the hydrostatic stress for the submodel loaded for 33,473 cycles under an applied load of $8 \mathrm{kN}$ ( $\mathrm{f}=0.25 \mathrm{~Hz}$ and $\mathrm{R}=0.1$ ). Heterogeneous stress distributions can be clearly observed and the maximum value of the local hydrostatic stress $(\sim 328 \mathrm{MPa})$ is about twice the global hydrostatic stress $(\sim 181 \mathrm{MPa})$. A close inspection shows that most stress concentrations are located at the triple or multiple points along grain boundaries due to the mismatch of the mechanical properties of multiple grains, which would 
generate large stress gradient and promote oxygen penetration. In the presence of stress, simulation of oxygen diffusion within the material is controlled by two essential parameters, namely, the oxygen diffusivity and the pressure factor $[34,36,37]$. So far, no direct measurements are available for oxygen diffusion parameters in nickel alloys. The present work measured the depth of internal oxidation under variable cyclic stress levels from the fatigue-oxidation tests on waisted specimens. The measurements have been subsequently used for the determination of the two essential parameters based on the simulation of oxygen penetration along grain boundaries under the influence of hetrogeneous ploycrystal plasticity deformation. The obtained diffusivity for temperature from $650^{\circ} \mathrm{C}$ to $800^{\circ} \mathrm{C}$ is on the order of $10^{-13}$ to $10^{-11} \mathrm{~mm} / \mathrm{s}^{2}$ and the pressure factor varies between $0.001585 \mathrm{MPa}^{-1}$ at $650^{\circ} \mathrm{C}$ and $0.188 \mathrm{MPa}^{-1}$ at $800^{\circ} \mathrm{C}$, both indicating a strong dependency on temperature. It should be noted that the FIB measurements do not really give the depth of oxygen diffusion but the depth of oxide. The depth of oxygen diffusion could be larger than the depth of oxide since oxygen can further penetrate along the grain boundaries without the formation of oxides. This work also assumes that the depth of oxygen diffusion follows a power law with a time exponent of $1 / 2$ (Eq. (13)), as opposed to a time exponent of 1/4 suggested in Reuchet and Remy [61] and Gustafsson et al. [62]. As explained in Kaur et al. [63], a 1/4-time exponent can be found when oxygen penetrates the crack tip not only from the grain boundaries but also from the bulk. Oxygen diffusivity, estimated from 1/4-exponent dependence, will increase by two to three orders when compared to that estimated from a parabolic law (i.e., 1/2-exponent).

Coupled with viscoplasticity, we simulated the oxygen diffusion process near a fatigue crack tip, where oxygen intake at the crack tip is given by Eq. (3), derived from the kinetics study (weight gain) of alloy RR1000 in Encinas-Oropesa et al. [28]. Our results showed that the oxygen level near the tip of a propagating crack seems to be of rather small magnitude (up to $1 \mu \mathrm{g} / \mathrm{mm}^{3}$ in Fig.10) at 
temperatures of interest (i.e., $650^{\circ} \mathrm{C}$ ). Consequently, attempts to examine the oxidation into crack tip would be very difficult, as the process also occurs over a small scale of distance. This is probably why no direct evidence of oxygen penetration into a crack tip has ever been reported in literature up to date. Some published work demonstrated only an indirect evidence of oxygen penetration into a propagating crack tip $[6,7,64]$. The majority of research work still tended to look at the oxide deposits on the fracture surfaces, which is considered as secondary as it occurs in the wake of crack growth. Nevertheless, in the current work, the simulated oxygen concentration ahead of the crack tip has been used to quantify the oxidation embrittlement near the crack tip, from which a failure curve has been constructed based on the consideration both fatigue deformation and oxidation damage. The crack growth rates in air at high-temperature can be predicted very well from the fatigueoxidation failure curve, although collecting experimental evidence of crack tip oxygen diffusion process and measurements of oxygen concentration near the crack tip are challenging tasks and yet to be accomplished. Oxygen diffusion process at a crack tip is a dynamic process, a combined effect of time, temperature and local deformation, and can be identified in terms of short and long range diffusion processes $[4,65]$, which has not been distinguished in the present simulation. The loading rates near the crack tip, which also play a role in the mechanism of oxygen-induced intergranular fracture $[9,10,66,67]$, were not considered in the oxygen diffusion simulation. Oxidation effects could occur primarily during the loading part of the cycle when the crack tip is in traction [9]. This aspect needs to be tackled in further work by considering the full interaction between oxygen diffusion and crack tip stress fields.

In creep-fatigue oxidation interaction, some authors suggested that the crack does not propagate during the hold time and that the acceleration in crack growth rate is related to the formation of an oxygen assisted damage zone ahead of the crack tip [e.g., 62]. Such phenomenon seems to be 
supported from our numerical simulations, as oxygen concentration increases drastically with the increase of dwell periods. However, in this work, the crack was predicted to grow at the time when the combined inelastic strain and oxygen concentration reach the failure curve, even during the hold period. It is also noticed that our model underestimates the crack growth rate for long-dwells (typically $>300$ s, Fig.12). As discussed earlier, the determination of diffusion parameters was based on the measured depth of oxides, rather than the depth of oxygen diffusion, using a parabolic law. This could give an underestimation of the diffusivity and the pressure factor, and hence weaken the effect of stress on diffusion, especially during the hold period with maximum stress level. Also in this work, diffusion of oxygen was modelled using a simplified approach, which considers only the influence of stress on diffusion without the full interaction between deformation and oxygen diffusion. Consequently, the growth stresses (may reach 1GPa [68] and contribute to crack growth) induced by oxidation itself was disregarded in our model. In addition, oxygen intake at the crack tip depends on the availability of oxygen in the vicinity of the crack tip, and could reach a peak state during the hold time when the crack tip is fully open, which has not been considered in the paper. Thus, further work is required to address these issues for model improvement, including the effects of curvature gradient introduced by the crack geometry (an additional driving force for mass transport $[69,70]$ ) and the grain boundary deformation (controlled mainly by sliding and diffusion [71]).

\section{Conclusions}

FIB secondary ion imaging showed the presence of internal oxides in alloy RR1000, indicating the oxygen penetration into the material. Cyclic stress was shown to have an influence on oxidation damage for temperatures at $750^{\circ} \mathrm{C}$ and above, and the depth of internal oxidation damage was enhanced by the increase of cyclic stress level. Finite element analyses of oxygen penetration along 
the grain boundaries have been carried out to obtain the diffusion parameters, which were subsequently used for modelling of the oxidation-assisted fatigue crack growth. A failure curve for crack growth under fatigue-oxidation condition has been constructed based on the consideration of both the accumulated inelastic strain and the oxygen concentration near the crack tip. Crack growth rates, predicted from the failure curve for selected frequencies and dwell periods, compare well with the experimental results.

\section{Acknowledgements}

The work was funded by the EPSRC (Grant EP/E062180/1) of the UK and in collaboration with Cranfield University (Professor J.R. Nicholls and Dr N.J. Simms) of the UK. The waisted specimens were provided by Rolls-Royce plc of the UK. Thanks are due to Dr A. Encinas-Oropesa and Mr A. Dyer for the assistance in the use of the FIB facilities at Cranfield University of the UK.

\section{References}

[1] R.H. Bricknell, D.A. Woodford, Acta Metall. 30 (1982) 257-264.

[2] G. Calvarin-Amiri, A.M. Huntz, R. Molins, Mater. High Temp. 18 (2001) 91-99.

[3] V. Garat, O. Brucelle, J.M. Cloue, V. Rebeyrolle, D. Monceau, B. Viguier, E. Andrieu, Mater. Sci. Forum 461-464 (2004) 537-544.

[4] E. Andrieu, R. Molins, Mater. Sci. Eng. A 154 (1992) 21-28.

[5] E. Andrieu, G. Hoshstetter, R. Molins, R. Pineau, in: T. Magnin (Ed.), Corrosion-Deformation Interactions (EFC 21), 1997, pp.461-475.

[6] C.F. Miller, G.W. Simmons, R.P. Wei, Scripta Mater. 44 (2001) 2405-2410.

[7] C.F. Miller, G.W. Simmons, R.P. Wei, Scripta Mater. 48 (2003) 103-108.

[8] J. Tong, S. Dalby, j. Byrne, J. Mater. Sci. 40 (2005) 1237-1243. 
[9] R. Molins, G. Hochestetter, J.C. Chassaigne, E. Andrieu, Acta Mater. 45 (1997) 663-674.

[10] L. Fournier, D. Delafosse, T. Magnin, Mater. Sci. Eng. A 316 (2001) 166-173.

[11] P. Hancock, R. Fletcher, Metallurgie 6 (1966) 1-9.

[12] D.A. Woodford, R.H. Bricknell, Treatise Mater. Sci. Tech. 25 (1983) 157-199.

[13] G. Moulin, P. Arevalo, A. Salleo, Oxid. Met. 45 (1996) 153-181.

[14] P. Berger, G. Moulin, M. Viennot, Nucl. Instrum. Meth. B 130 (1997) 717-721.

[15] P. Berger, L. Gaillet, R. El Tahhann, G. Moulin, M. Viennot, Nucl. Instrum. Meth. B 181 (2001) 382-388.

[16] C.H. Zhou, H.T. Ma, L. Wang, Corros. Sci. 52 (2010) 210-215.

[17] M. Reger, L. Remy, Metall. Trans. A 19 (1988) 2259-2268.

[18] U. Krupp, Shreir's Corrosion 1 (2010) 304-315.

[19] Z. Azari, M. Abbadi, H. Moustabchir, M. Lebienven, Int. J. Fatigue 30 (2008) 517-527.

[20] B. Fournier, M. Sauzay, C. Caës, M. Noblecourt, M. Mottot, A. Bougault, V. Rabeau, A. Pineau, Int. J. Fatigue 30 (2008) 649-662.

[21] C. Stöcker, M. Zimmermann, H.-J.Christ, Z.L. Zhan, C. Cornet, L.G. Zhao, M.C. Hardy, J. Tong, Mater. Sci. Eng. A 518 (2009) 27-34.

[22] J. Tong, S. Dalby, J. Byrne, M. Henderson, M.C. Hardy, Int. J. Fatigue 23 (2001) 897-902 .

[23] L.G. Zhao, J. Tong, B. Vermeulen, J. Byrne, Mech. Mater. 33 (2001) 593-600.

[24] S. Dalby, J. Tong, J. Mater. Sci. 40 (2005) 1217-1228.

[25] Z.L. Zhan, J. Tong, Mech. Mater. 39 (2007) 64-72.

[26] Z.L. Zhan, J. Tong, Mech. Mater. 39 (2007) 73-80.

[27] L.G. Zhao, J. Tong, J. Mech. Phys. Solids 56 (2008) 3363-3378. 
[28] A. Encina-Oropesa, G.L. Drew, M.C. Hardy, A.J. Leggett, J.R. Nicholls, N.J. Simms, Effects of oxidation and hot corrosion in a nickel disc alloy, the 11th International Symposium on Superalloys, Champion, Pennsylvania, USA, 14 18 September 2008.

[29] A. Karabela, L.G. Zhao, J. Tong, N.J. Simms, J.R. Nicholls, M.C. Hardy, Mater. Sci. Eng A 528 (2011) 6194-6202.

[30] A. Karabela, An experimental and computational study of damage and crack growth for a nickel-based superalloy under fatigue-oxidation conditions, $\mathrm{PhD}$ thesis, University of Portsmouth, UK, 2011.

[31] S. Dalby, The effects of frequency and waveshape on the fatigue crack growth of an advanced nickel based superalloy at elevated temperatures, $\mathrm{PhD}$ thesis, University of Portsmouth, UK, 2005.

[32] J.A. Pfaendtner, c.J. McMahon Jr., Acta Mater. 49 (2001) 3369-3377.

[33] U. Krupp, W.M. Kane, C. Laird, C.J. McMahon Jr., Mater. Sci. Eng. A 387-389 (2004) 409413.

[34] U. Krupp, Int. Mater. Rev. 50 (2005) 83-97.

[35] D. Bika, C.J. McMahon Jr., Acta Metall. Mater. 43 (1995) 1909-1916.

[36] F.L. Carranza, R.B. Haber, J. Mech. Phys. Solids 47 (1999) 27-58.

[37] L.G. Zhao, J. Tong, M.C. Hardy, Eng. Fract. Mech. 77 (2010) 925-938.

[38] J.C.M. Li, R.A. Oriani, L.S. Darken, Z Phys. Chem. Neue Folge 49 (1966) 271-290.

[39] F.C. Larché, J.W. Cahn, Acta Metall. 30 (1982) 1835-1845.

[40] G.B. Stephenson, Acta Metall. 36 (1988) 2663-2683.

[41] A.T. Yokobori Jr., Y. Chinda, T. Nemoto, K. Satoh, T. Yamada, Corros. Sci. 44 (2002) 407424.

[42] L.G. Zhao, ASME J. Eng. Mater. Tech. 133 (2011) 031002. 
[43] J.L. Chaboche, Int. J. Plasticity 5 (1989) 247-302.

[44] E.P. Busso, Cyclic deformation of monocrystalline nickel aluminide and high temperature coatings, PhD thesis, Massachusetts Institute of Technology, Cambridge, MA, USA, 1990.

[45] R.J. Dennis, Mechanistic modelling of deformation and void growth behaviour in superalloy single crystals, PhD thesis, Imperial College London, UK, 2000.

[46] ABAQUS, 2011, Version 6.11, Dassault Systemes Simulia Corp., Providence, USA.

[47] E.P. Busso, F.T. Meissonnier, N.P. O’Dowd, J. Mech. Phys. Solids 48 (2000) 2333-2361.

[48] F.T. Meissonnier, E.P. Busso, N.P. O’Dowd, Int. J. Plasticity 17 (2001) 601-640.

[49] Zhan ZL. A study of cyclic plasticity and viscoplasticity in a new nickel-based superalloy using unified constitutive equations, PhD thesis, University of Portsmouth, UK; 2004.

[50] B. Lin, L.G. Zhao, J. Tong, H.-J. Christ, Mater. Sci. Eng. A 527 (2010) 3581-3587.

[51] B. Lin, L.G. Zhao, J. Tong, Eng. Fract. Mech. 78(2011) 2174-2192.

[52] C. Cornet, L.G. Zhao, J. Tong, Eng. Fract. Mech. 76 (2009) 2538-2553.

[53] J. Tong, L.G. Zhao, B. Lin, Int. J. Fatigue, 2012, in press.

[54] H. Riedel, J.R. Rice, Tensile cracks in creeping solids. ASTM STP 700 (1980) 112-130.

[55] M. Yatomi, K.M. Nikbin, N.P. O’Dowd, Int. J. Pressure Vessels Piping 80 (2003) 573-583.

[56] L.G. Zhao, N.P. O’Dowd, E.P. Busso, E.P., J. Mech. Phys. Solids 54 (2006) 288-309.

[57] R.O. Ritchie, A.W. Thompson, Metall. Trans. A 16 (1985) 236-248.

[58] J.H. Chen, P.M. Rogers, J.A. Little, Oxid. Met. 47 (1997) 381-410.

[59] V.B. Trindade, U. Krupp, Ph.E.-G. Wagenhuber, Y.M. Virkar, H.-J. Christ, Mater. High Temp. $22(2005)$ 207-212.

[60] D.P. Whittle, Y. Shida, G.C. Wood, F.H. Stott, Philos. Mag. A 46 (1982) 931-949.

[61] J. Reuchet, L. Remy, Metall. Trans. A 14(1983), 141-149. 
[62] D. Gustafsson, J. Moverare, K. Simonsson, S. Johansson, M. Hörnqvist, T. Månsson, S Sjöström, Procedia Eng. 10(2011), 2821-2826.

[63] I. Kaur, Y. Mishin, W. Gust, Fundamentals of grain and interface boundary diffusion, John Wiley, 1995.

[64] R.P. Wei, C. Miller, Z. Huang, G.W. Simmons, D.G. Harlow, Eng Fract. Mech. 76 (2009) 715727.

[65] H. Ghonem, T. Nicholas, A. Pineau, Fatigue Fract. Eng Mater. Struct. 16 (1993) 577-590.

[66] M. Clavel, A. Pineau, Metall. Mater. Trans. A 9 (1978) 471-480.

[67] H. Andersson, C. Persson, Int. J. Fatigue 23 (2001) 817-827.

[68] Z. Suo, D.V. Kubair, A.G. Evans, D.R. Clarke, V.K. Tolpygo, Acta Mater. 51 (2003) 959-974.

[69] H. El Kadiri, M.F. Horstemeyer, D.J. Bammann, J. Mech. Phys. Solids 56 (2008) 3392-3415

[70] F.Y. Génin, W.W. Mullins, P. Wynblatt, Acta Metall. Mater. 41 (1993) 3541-3547.

[71] A.F. Bower, E. Wininger, J. Mech. Phys. Solids 52 (2004) 1289-1317. 


\section{Figure Captions}

Figure 1, The waisted specimen geometry and the three positions "A", "B" and "C" selected for FIB examination. All dimensions are in $\mathrm{mm}$.

Figure 2, (a) 3D RVE model and (b) comparison of simluations against test results for stress-strain loop at the first cycle (strain rate $=0.05 \% / \mathrm{s}$, strain range $=2 \%, \mathrm{~T}=650^{\circ} \mathrm{C}$ )

Figure 3, (a) Finite element mesh for the global model, (b) The 150-grain submodel with random grain orientation and (c) the inverse pole figure for the 150 grains.

Figure 4, (a) The finite element model for a CT specimen and (b) the refined mesh for the crack tip area (element size is $6.35 \mu \mathrm{m}$ ).

Figure 5, FIB secondary ion images for position "A" (Figure 1) at (a) $700^{\circ} \mathrm{C}$ (b) $750^{\circ} \mathrm{C}$ and (c) $800^{\circ} \mathrm{C}$, where the dashed line indicates the original specimen surface.

Figure 6, Comparison of oxidation penetration at position (a) "B" and (b) "C" (Figure 1) at $800^{\circ} \mathrm{C}$, where the dashed line indicates the original specimen surface.

Figure 7, Comparison of the depths of internal oxidation at positions A, B and C (Figure 1) at $700^{\circ} \mathrm{C}$, $750^{\circ} \mathrm{C}$ and $800^{\circ} \mathrm{C}$.

Figure 8, Simulated oxygen concentration at $800^{\circ} \mathrm{C}$ after 33473 cycles for (a) natural diffusion and (b) a pressure factor of $0.3 \mathrm{MPa}^{-1}$.

Figure 9, The depth of oxygen penetration against the pressure factor for $\mathrm{T}=(\mathrm{a}) 750^{\circ} \mathrm{C}$ and (b) $800^{\circ} \mathrm{C}$, where the penetration depth $\delta$ under fatigue is normalised using the penetration depth $\delta_{0}$ for natural diffusion. 
Figure 10, Failure curve in terms of the accumulated inelastic strain and the oxygen concentration near the crack tip.

Figure 11, The effects of loading frequency on the crack growth rate for a triangular waveform with $\Delta \mathrm{K}=30 \mathrm{MPa} \sqrt{\mathrm{m}}_{\text {(a) }}$ and $40 \mathrm{MPa} \sqrt{\mathrm{m}}_{\text {(b) }}$ and load ratio $\mathrm{R}=0.1$ at $650^{\circ} \mathrm{C}$; comparison of the model prediction against the experimental results $[24,31]$.

Figure 12, The effects of dwell period on the crack growth rate for a trapezoidal $(1-\mathrm{x}-1-1, \mathrm{x}=$ dwell time) loading waveform with $\Delta \mathrm{K}=$ (a) $30 \&$ (b) $40 \mathrm{MPa} \sqrt{\mathrm{m}}$ and load ratio $\mathrm{R}=0.1$ at $650^{\circ} \mathrm{C}$; comparison of the model prediction against the experimental results [24, 31].

Figure 13, Contour plot of the hydrostatic stress (peak load level) in the submodel after 33473 cycles for an applied load of $8 \mathrm{kN}$. 


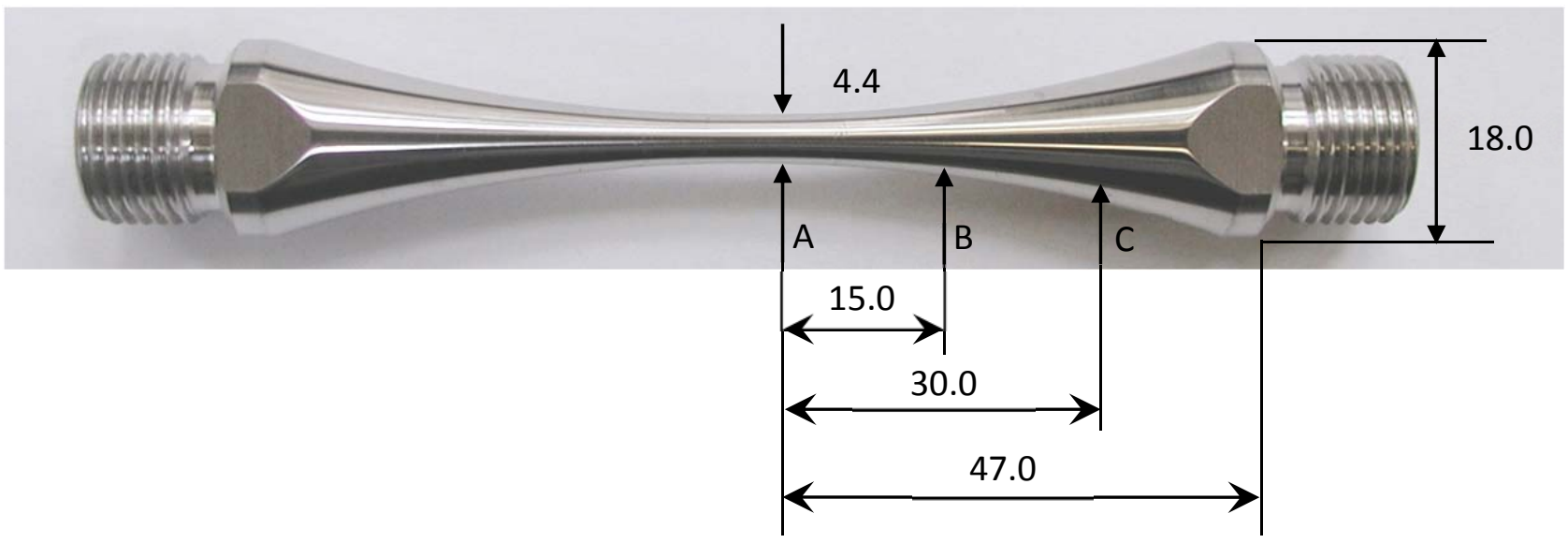

Figure 1, The waisted specimen geometry and the three positions " $\mathrm{A}$ ", "B" and " $\mathrm{C}$ " selected for FIB examination. All dimensions are in $\mathrm{mm}$. 


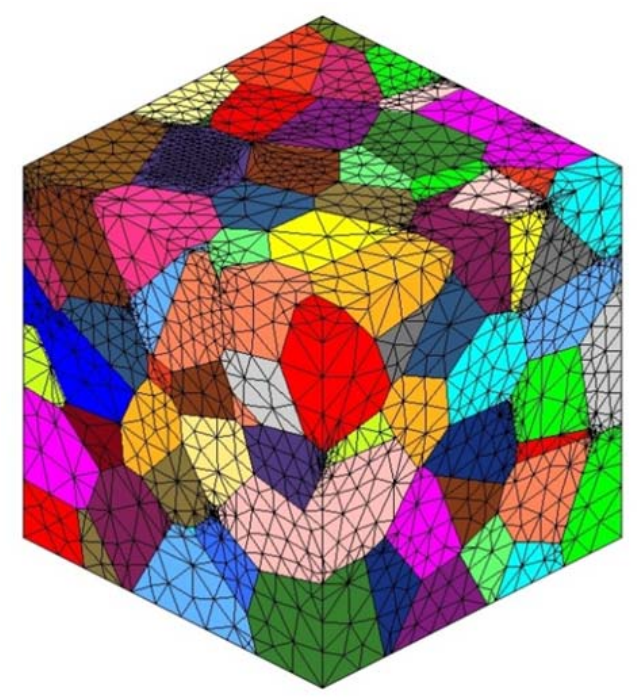

(a)

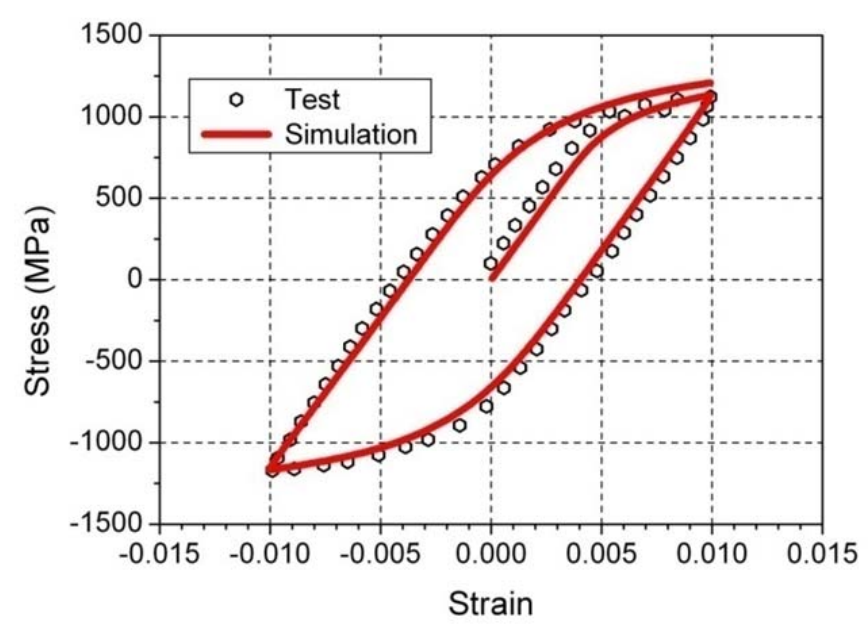

(b)

Figure 2, (a) 3D RVE model and (b) comparison of simluations against test results for stress-strain loop at the first cycle (strain rate $=0.05 \% / \mathrm{s}$, strain range $=2 \%, \mathrm{~T}=650^{\circ} \mathrm{C}$ ) 


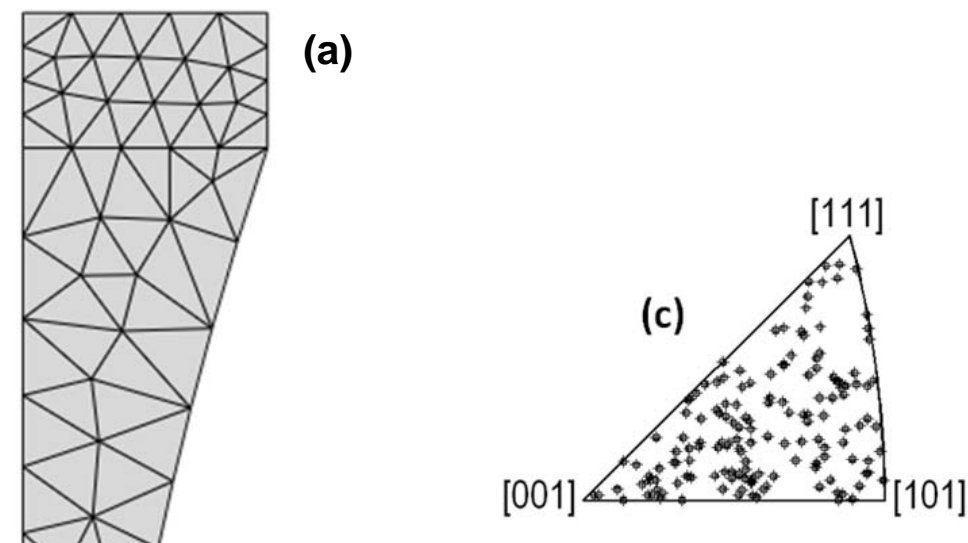

(b)

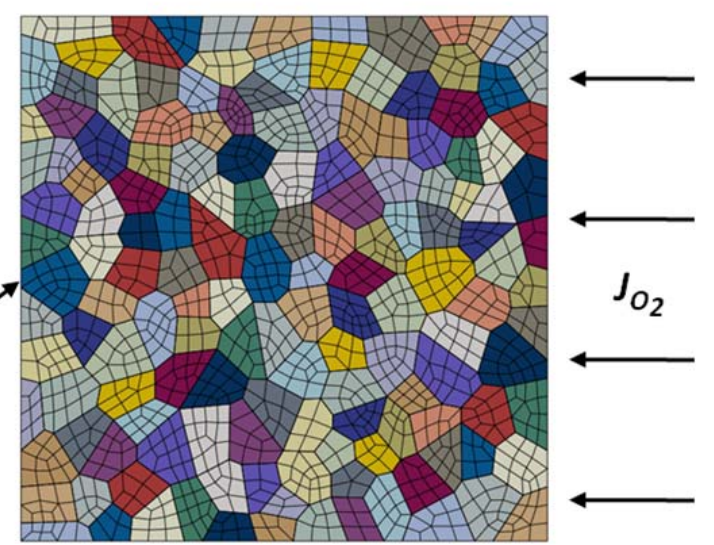

Figure 3, (a) Finite element mesh for the global model, (b) The 150-grain submodel with random grain orientation and (c) the inverse pole figure for the 150 grains. 


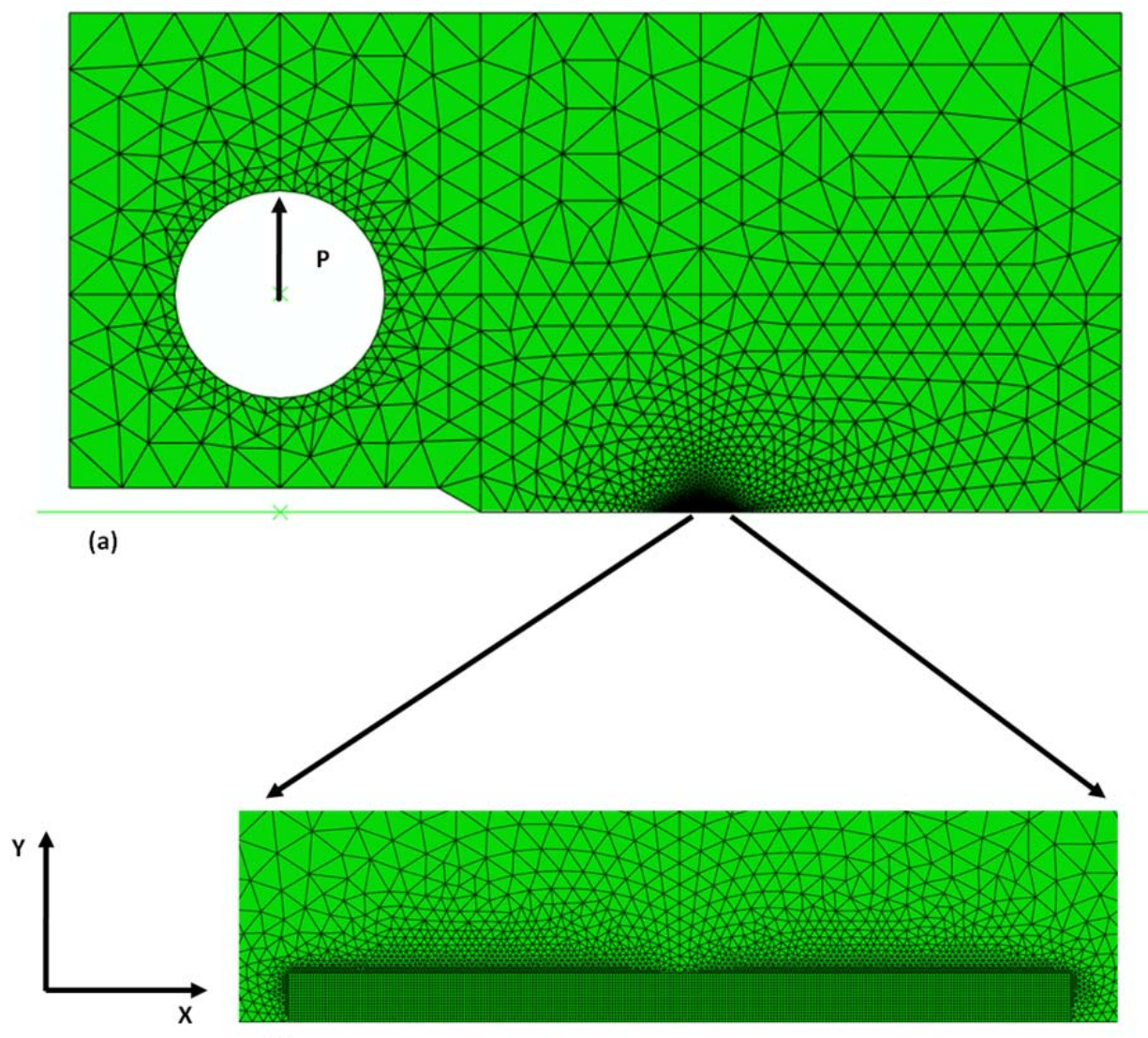

(b)

Figure 4, (a) The finite element model for a CT specimen and (b) the refined mesh for the crack tip area (element size is $6.35 \mu \mathrm{m}$ ).

(a) 


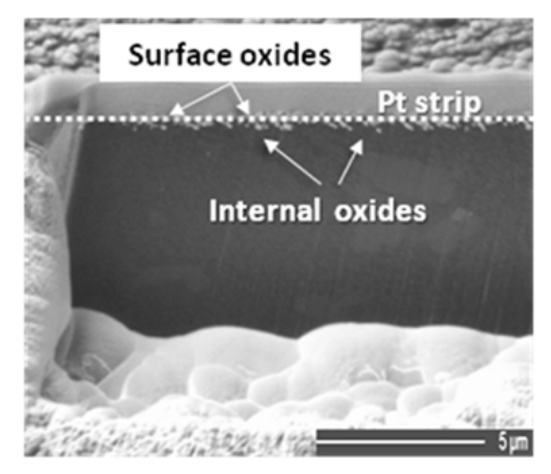

(b)

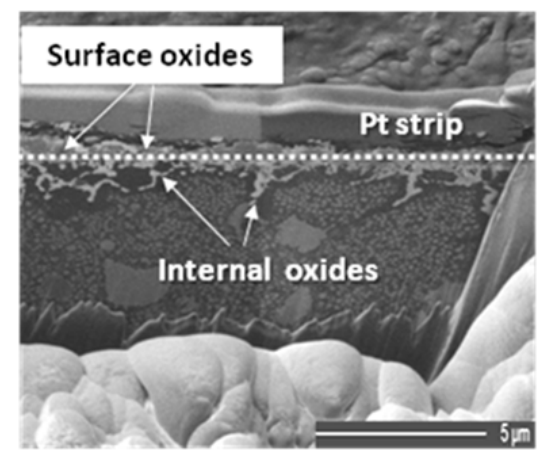

(c)

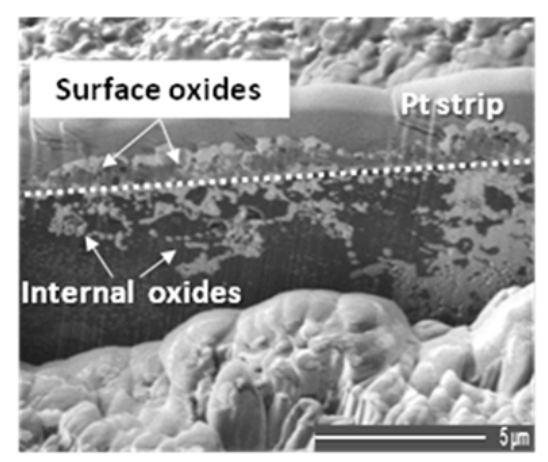

Figure 5, FIB secondary ion images for position "A" (Figure 1) at (a) $700^{\circ} \mathrm{C} \mathrm{(b)} 750^{\circ} \mathrm{C}$ and (c) $800^{\circ} \mathrm{C}$, where the dashed line indicates the original specimen surface. 
(a)

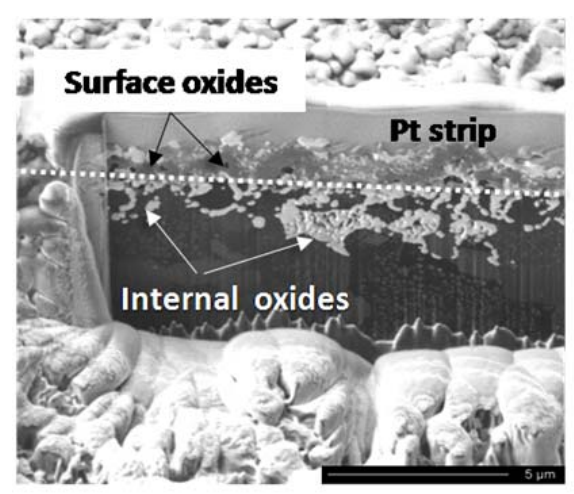

(b)

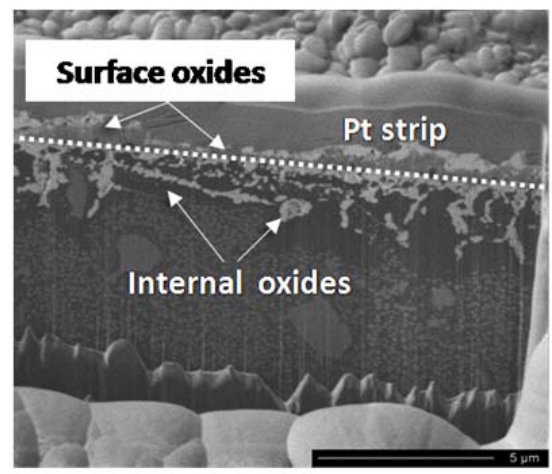

Figure 6, Comparison of oxidation penetration at position (a) "B" and (b) "C" (Figure 1) at $800^{\circ} \mathrm{C}$, where the dashed line indicates the original specimen surface. 


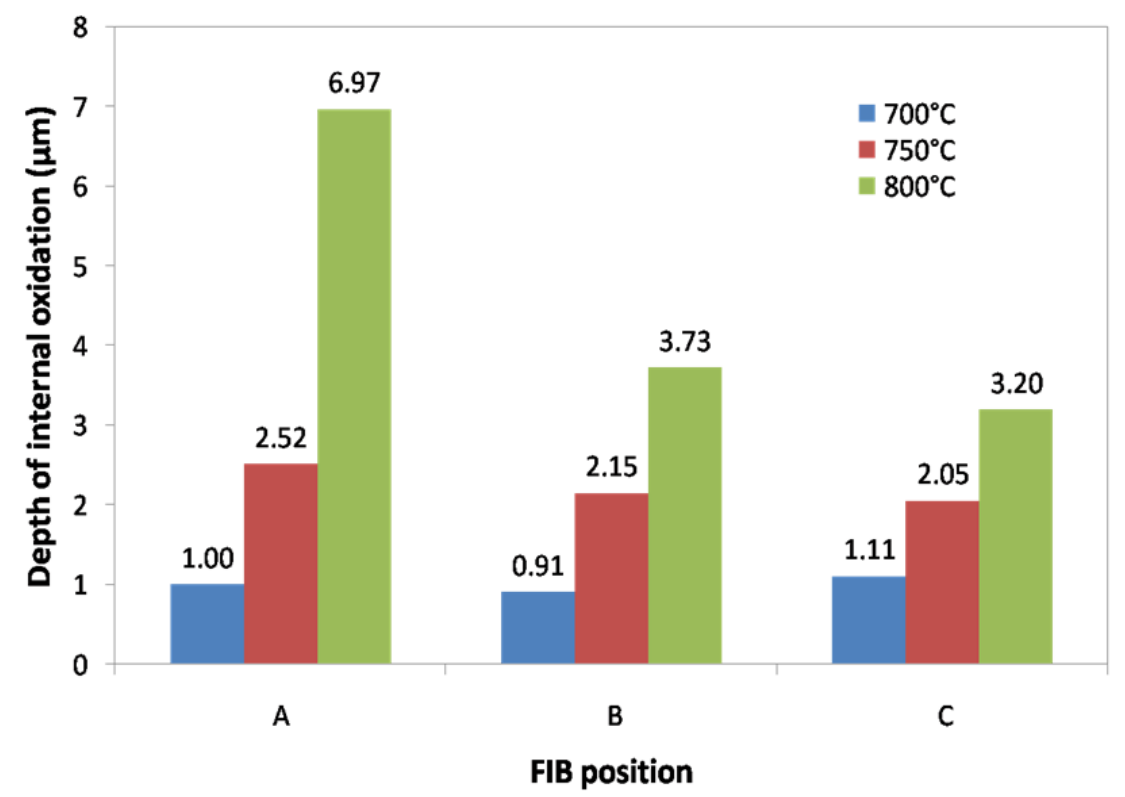

Figure 7, Comparison of the depths of internal oxidation at positions A, B and C (Figure 1) at $700^{\circ} \mathrm{C}$, $750^{\circ} \mathrm{C}$ and $800^{\circ} \mathrm{C}$. 

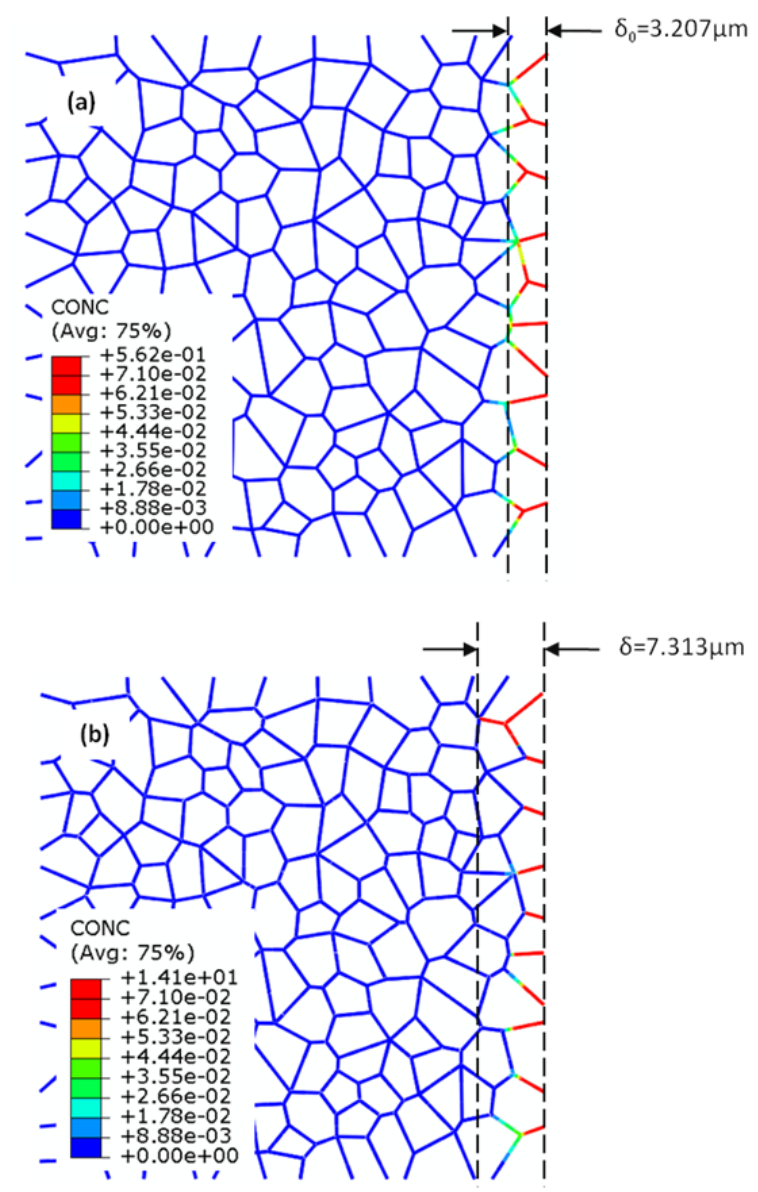

Figure 8 , Simulated oxygen concentration at $800^{\circ} \mathrm{C}$ after 33473 cycles for (a) natural diffusion and (b) a pressure factor of $0.3 \mathrm{MPa}^{-1}$. 


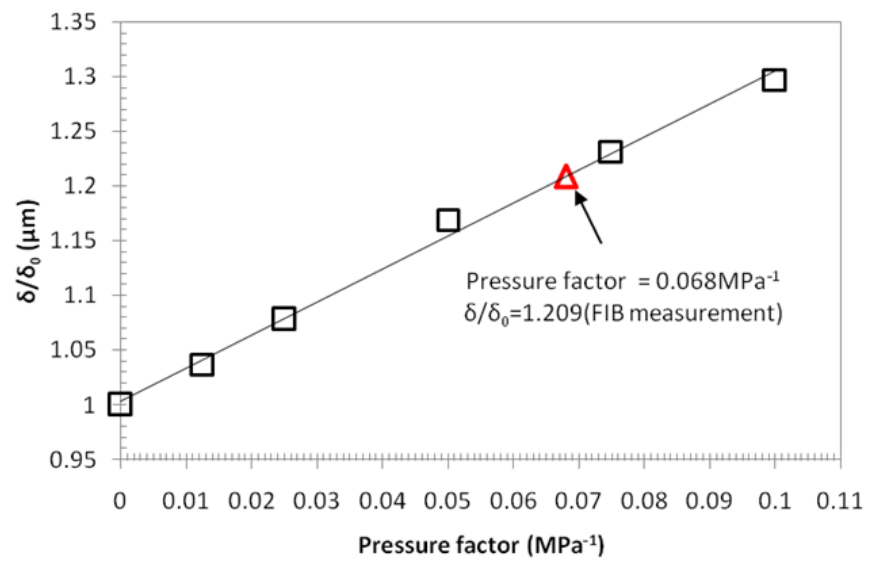

(a)

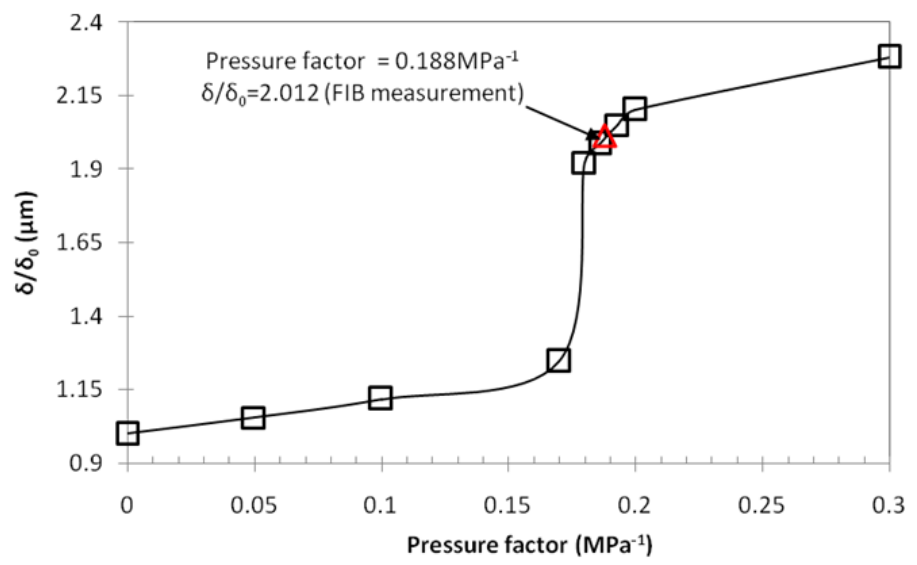

(b)

Figure 9, The depth of oxygen penetration against the pressure factor for $\mathrm{T}=$ (a) $750^{\circ} \mathrm{C}$ and (b) $800^{\circ} \mathrm{C}$, where the penetration depth $\delta$ under fatigue is normalised using the penetration depth $\delta_{0}$ for natural diffusion. 


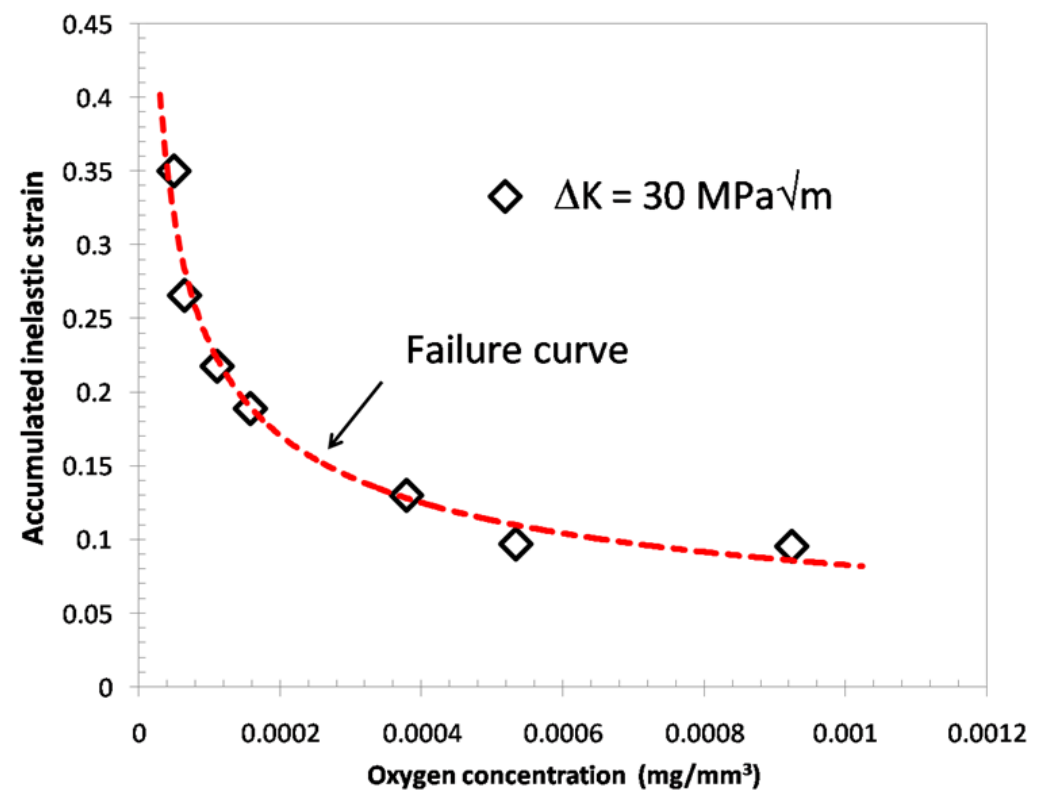

Figure 10, Failure curve in terms of the accumulated inelastic strain and the oxygen concentration near the crack tip. 


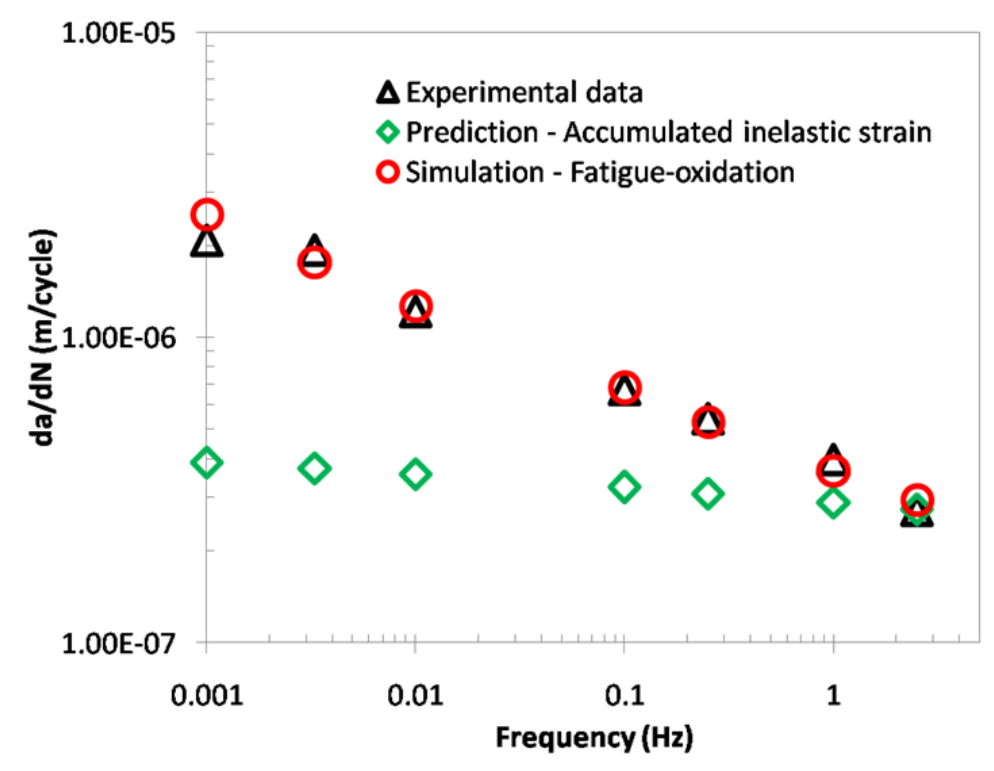

(a)

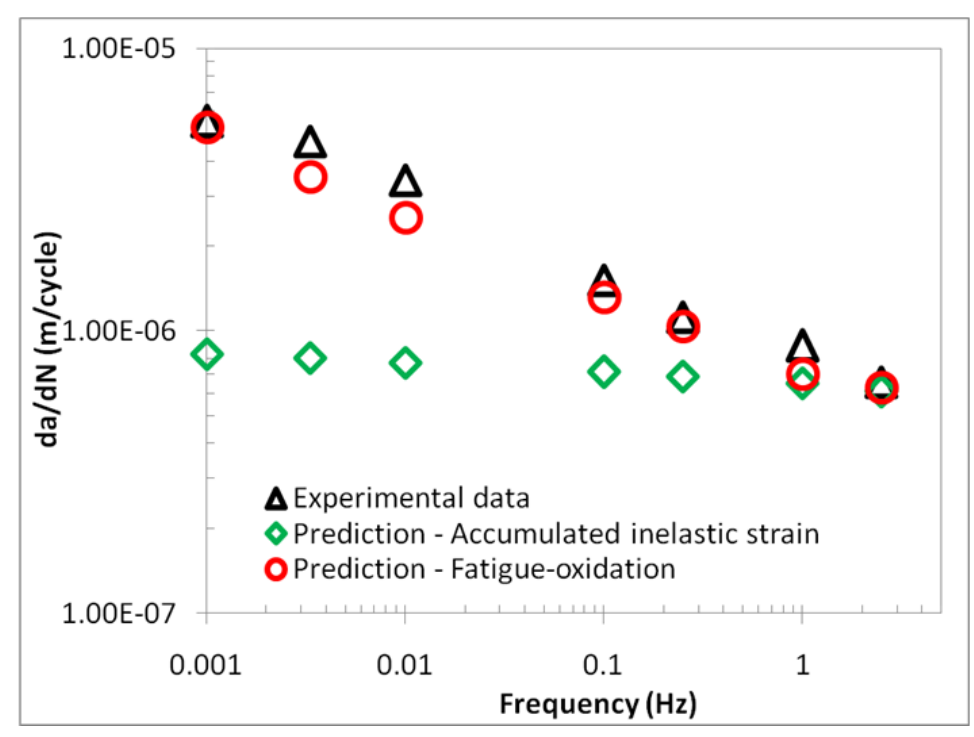

(b)

Figure 11, The effects of loading frequency on the crack growth rate for a triangular waveform with $\Delta \mathrm{K}=30 \mathrm{MPa} \sqrt{\mathrm{m}}_{\text {(a) }}$ and $40 \mathrm{MPa} \sqrt{\mathrm{m}}_{\text {(b) }}$ and load ratio $\mathrm{R}=0.1$ at $650^{\circ} \mathrm{C}$; comparison of the model prediction against the experimental results $[24,31]$. 


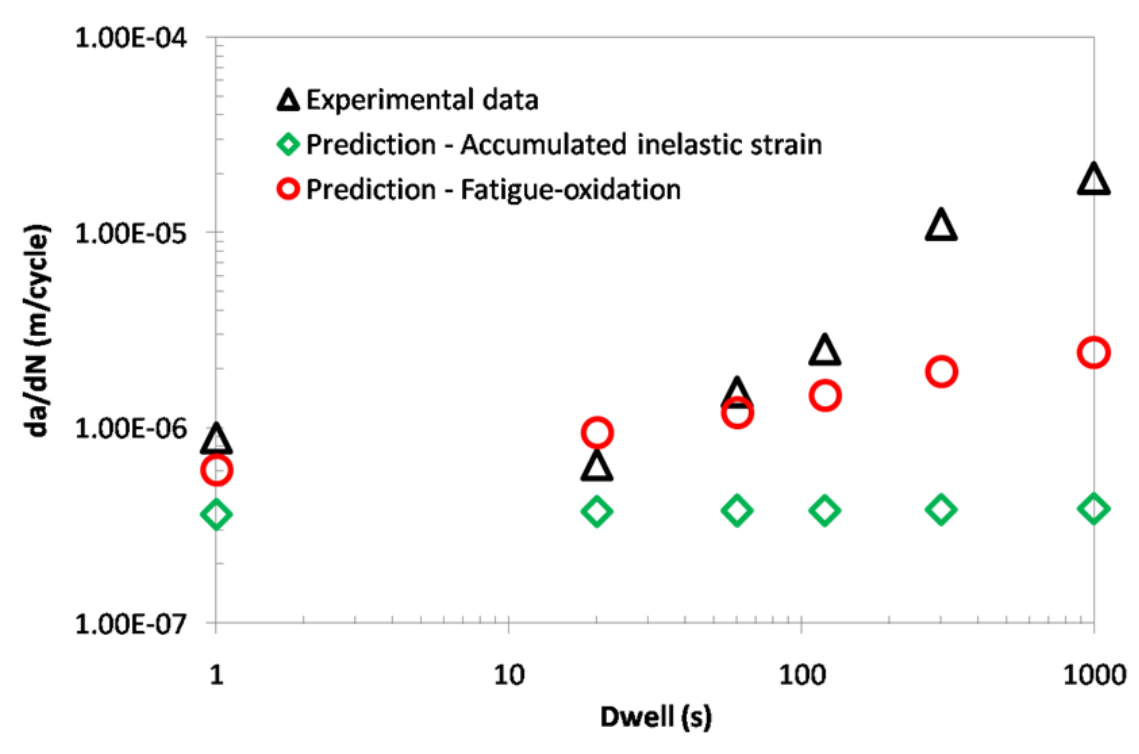

(a)

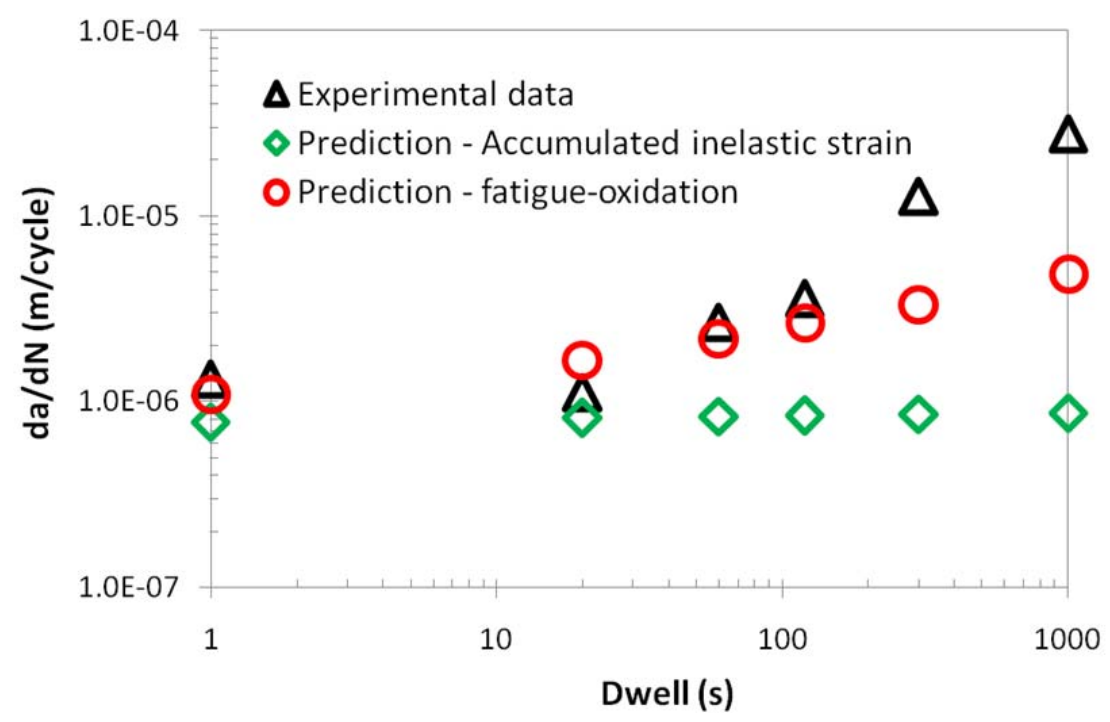

(b)

Figure 12, The effects of dwell period on the crack growth rate for a trapezoidal $(1-\mathrm{x}-1-1, \mathrm{x}=$ dwell time) loading waveform with $\Delta \mathrm{K}=$ (a) $30 \&$ (b) $40 \mathrm{MPa} \sqrt{\mathrm{m}}_{\mathrm{m}}$ and load ratio $\mathrm{R}=0.1$ at $650^{\circ} \mathrm{C}$; comparison of the model prediction against the experimental results [24, 31]. 


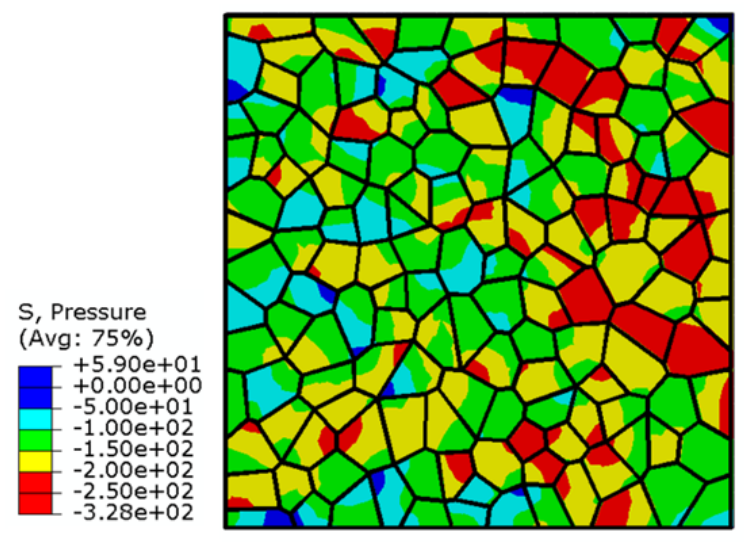

Figure 13, Contour plot of the hydrostatic stress (peak load level) in the submodel after 33473 cycles for an applied load of $8 \mathrm{kN}$. 
Table captions

Table 1. Values of the material parameters for the viscoplastic constitutive model at $650^{\circ} \mathrm{C}[49]$.

Table 2. Values of the material parameters for the crystal plasticity constitutive model at $650^{\circ} \mathrm{C}$.

Table 3. The oxygen diffusivity at four temperatures.

Table 4. The pressure factor at four temperatures. 
Table 1. Values of the material parameters for the viscoplastic constitutive model at $650^{\circ} \mathrm{C}$ [49].

\begin{tabular}{ll}
\hline Parameters & Optimised values \\
\hline$E(\mathrm{GPa})$ & 190 \\
\hline$v$ & 0.285 \\
\hline$b$ & 7.13 \\
\hline$Q(\mathrm{MPa})$ & 161.52 \\
\hline$a_{1}(\mathrm{MPa})$ & 361.57 \\
\hline$C_{1}$ & 391.61 \\
\hline$a_{2}(\mathrm{MPa})$ & 266.84 \\
\hline$C_{2}$ & 2578.69 \\
\hline$Z$ & 678.317 \\
\hline$n$ & 15.496 \\
\hline$k_{0}(\mathrm{MPa})$ & 144.26 \\
\hline
\end{tabular}


Table 2. Values of the material parameters for the crystal plasticity constitutive model at $650^{\circ} \mathrm{C}$.

\begin{tabular}{|c|c|c|}
\hline Parameters & Octahedral slip & Cubic slip \\
\hline$F_{0}\left(\mathrm{kJmol}^{-1}\right)$ & 310 & 310 \\
\hline$p_{0}$ & 0.34 & 0.99 \\
\hline$q_{0}$ & 1.8 & 1.5 \\
\hline$\dot{\gamma}_{0}\left(\mathrm{~s}^{-1}\right)$ & 120 & 4 \\
\hline$\hat{\tau}_{0}(\mathrm{MPa})$ & 1200 & 810 \\
\hline$S_{0}(\mathrm{MPa})$ & 380 & 50 \\
\hline$f_{\mathrm{C}}$ & 0.38 & 0.18 \\
\hline$b_{\mathrm{B}}(\mathrm{GPa})$ & 30 & 100 \\
\hline$h_{\mathrm{S}}(\mathrm{GPa})$ & 160 & 4.5 \\
\hline$d_{\mathrm{D}}$ & 2210 & 22 \\
\hline$\mu_{0}^{\prime}(\mathrm{GPa})$ & 69.5 & 27.5 \\
\hline
\end{tabular}


Table 3. The oxygen diffusivity at four temperatures.

\begin{tabular}{|c|c|}
\hline $\mathrm{T}\left({ }^{\circ} \mathrm{C}\right)$ & $\mathrm{D}\left(\mathrm{mm}^{2} / \mathrm{s}\right)$ \\
\hline 650 & $1.085 \mathrm{e}-13$ \\
\hline 700 & $1.397 \mathrm{e}-12$ \\
\hline 750 & $5.859 \mathrm{e}-12$ \\
\hline 800 & $1.423 \mathrm{e}-11$ \\
\hline
\end{tabular}

Table 4. The pressure factor at four temperatures.

\begin{tabular}{|c|c|}
\hline $\mathrm{T}\left({ }^{\circ} \mathrm{C}\right)$ & $\mathrm{M}\left(\mathrm{MPa}^{-1}\right)$ \\
\hline 650 & 0.001585 \\
\hline 700 & 0.0098 \\
\hline 750 & 0.068 \\
\hline 800 & 0.188 \\
\hline
\end{tabular}

